University of Wollongong

Research Online

Faculty of Engineering and Information

Faculty of Engineering and Information

Sciences - Papers: Part B

Sciences

2017

Impact of structural design solutions on the energy and thermal

performance of an Australian office building

Mehdi Robati

University of Wollongong, mrobati@uow.edu.au

Georgios Kokogiannakis

University of Wollongong, gkg@uow.edu.au

Timothy J. McCarthy

University of Wollongong, timmc@uow.edu.au

Follow this and additional works at: https://ro.uow.edu.au/eispapers1

Part of the Engineering Commons, and the Science and Technology Studies Commons

Research Online is the open access institutional repository for the University of Wollongong. For further information contact the UOW Library: research-pubs@uow.edu.au 


\title{
Impact of structural design solutions on the energy and thermal performance of an Australian office building
}

\begin{abstract}
Concrete is a heavyweight construction material whose high thermal mass could increase the thermal storage capacity of a building envelope and in turn affect indoor thermal comfort. Selecting an appropriate method for concrete construction and form could also affect the total energy performance and thermal comfort of a building, a fact that is often overlooked by structural engineers. This study presents the results of energy simulations of the potential impact that concrete construction forms, in particular two slab types, and structural materials have on the energy consumption of archetypal commercial office buildings in five major Australia cities (Sydney, Melbourne, Canberra, Brisbane and Darwin). This study has three stages: 1 ) a structural analysis of two slab types (Flat and Waffle slab); 2) the selection of two types of structural concrete (conventional Normal weight concrete and novel Ultralightweight concrete); 3 ) a comparative analysis to quantify the magnitude of the change in predicted annual energy consumption due to changes in the form of construction and the type of structural concrete. The energy simulation results showed that the thermal energy performance of the building was influenced by structural materials and slab types. It is shown that the thermal capacity of the concrete construction forms can be utilized to shift thermal loads, reduce peak demand and reduce operational energy consumption. The selection of an appropriate concrete type was more important in terms of energy performance in the coldest (Melbourne and Canberra) and hottest (Darwin) climate zones of this study.
\end{abstract}

\section{Keywords}

performance, thermal, energy, solutions, design, building, structural, office, impact, australian

\author{
Disciplines \\ Engineering | Science and Technology Studies
}

\section{Publication Details}

Robati, M., Kokogiannakis, G. \& McCarthy, T. J. (2017). Impact of structural design solutions on the energy and thermal performance of an Australian office building. Building and Environment, 124 258-282. 
Impact of structural design solutions on the energy and thermal performance of an Australian office building.

\author{
Mehdi Robati ${ }^{* 1,}$, , Georgios Kokogiannakis ${ }^{1}$, Timothy J McCarthy ${ }^{2}$ \\ ${ }^{1}$ Sustainable Buildings Research Centre (SBRC), University of Wollongong, Australia \\ ${ }^{2}$ School of Civil, Mining and Environment, Faculty of Engineering and Information Sciences, \\ University of Wollongong, Australia \\ *Corresponding author. Tel.: +61 420477662. \\ E-mail address: mr329@uowmail.edu.au (Mehdi Robati)
}

\begin{abstract}
Concrete is a heavyweight construction material whose high thermal mass could increase the thermal storage capacity of a building envelope and in turn affect indoor thermal comfort. Selecting an appropriate method for concrete construction and form could also affect the total energy performance and thermal comfort of a building, a fact that is often overlooked by structural engineers. This study presents the results of energy simulations of the potential impact that concrete construction forms, in particular two slab types, and structural materials have on the energy consumption of archetypal commercial office buildings in five major Australia cities (Sydney, Melbourne, Canberra, Brisbane and Darwin). This study has three stages: 1) a structural analysis of two slab types (Flat and Waffle slab); 2) the selection of two types of structural concrete (conventional Normal weight concrete and novel Ultralightweight concrete); 3) a comparative analysis to quantify the magnitude of the change in predicted annual energy consumption due to changes in the form of construction and the type of structural concrete. The energy simulation results showed that the thermal energy performance of the building was influenced by structural materials and slab types. It is shown that the thermal capacity of the concrete construction forms can be utilized to shift thermal loads, reduce peak demand and reduce operational energy consumption. The selection of an appropriate concrete type was more important in terms of energy performance in the coldest (Melbourne and Canberra) and hottest (Darwin) climate zones of this study.
\end{abstract}

Keyword: Energy efficiency, Ultra-lightweight concrete, Office building, Structural design, 


\section{Introduction}

The structural design of buildings is traditionally limited to material specifications and structural efficiency, whereas structural engineering research often attempts to provide structural efficiency by reducing the materials and resources used while increasing the longevity of structures through design. However, with the aim continuous innovation in the structural design of buildings a new model provides a framework to integrate the long-term behaviour of materials and systems into the design process; indeed modern integrated structural design could utilise life cycle assessment tools to determine the whole life environmental performance of building design because life cycle energy assessments promote a more efficient use of materials and energy.

The appropriate choice of construction and building materials can potentially reduce the life cycle energy of buildings because materials with low thermal conductivity help to reduce the demand for energy as well as the associated greenhouse gases (GHG) [1]. For instance, concrete is one of the main construction materials with the ability to absorb and retain energy for a long period of time; action that reduces energy consumption by storing heat in a natural daily cycle (thermal mass). The mass components reduce temperature fluctuations in building spaces and thus reduce the associated peak heating or cooling loads [1]. Previous studies indicate that the thermal conductivity of concrete varies across Normal, Lightweight, and Ultralightweight concrete [2-6]; this variation in density stems from changes in the proportion and type of aggregates, and the cementitious materials in the concrete mixture.

Normal weight concrete with a density between 2,200 to $2,600 \mathrm{~kg} / \mathrm{m}^{3}$ includes cement, normal weight aggregates, and water, whereas lightweight concrete (1,350 to 
$1,900 \mathrm{~kg} / \mathrm{m}^{3}$ ) is produced by replacing some of the solid materials in the mix with air voids [7]. There are three possible locations for the air voids, inside the particles of aggregate, inside the cement paste, and between the coarse aggregate particles [7]. The potential for substituting ordinary Portland cement with geopolymer materials in Lightweight concrete has been studied extensively by researchers [6, 8]. Geopolymer concrete is synthesised by mixing aluminosilicate material, alkali solutions, and water [9]. Also, the potential use of Lightweight hollow spheres in the design mix is a technique for producing Ultra-lightweight concrete $\left(1,154\right.$ to $\left.1,471 \mathrm{~kg} / \mathrm{m}^{3}\right)$; in fact ultra-lightweight concrete consists mainly of lightweight hollow spheres (cenosphere materials), water, and a binder (it also includes silica fume and Portland cement) [3, 6].

The thermal properties of a concrete mix are influenced by the thermal properties of ingredients such as cement, aggregates, and the moisture existing in the mix [10]. The replacement of normal aggregate with lightweight aggregates reduces the density and thermal conductivity of concrete. A brief review of previously published values (Table 1) shows that the estimated thermal conductivity of Normal, Lightweight, and Ultra-lightweight concrete could vary from $3.1 \mathrm{~W} / \mathrm{mK}$ to 0.28 $\mathrm{W} / \mathrm{mK}[2-6,11-15]$. 
Table 1 Thermo-physical and structural properties of concrete classes as reported in the literature

\begin{tabular}{|c|c|c|c|c|}
\hline References & Density $\left(\mathrm{kg} / \mathrm{m}^{3}\right)$ & $\begin{array}{l}\text { Compressive } \\
\text { strength } \\
(\mathrm{MPa})\end{array}$ & $\begin{array}{c}\text { Thermal } \\
\text { conductivity } \\
(\mathrm{W} / \mathrm{mK})\end{array}$ & $\begin{array}{l}\text { Type of } \\
\text { concrete }\end{array}$ \\
\hline Wu et al. (2015) & $966-2,251$ & $33-69.4$ & $0.28-1.98$ & $\begin{array}{c}\text { Normal, } \\
\text { Lightweight } \\
\text { and Ultra- } \\
\text { Lightweight }\end{array}$ \\
\hline Blanco et al. (2000) & $1,090-1,510$ & $5.04-33.03$ & $0.46-0.69$ & Lightweight \\
\hline Uysal et al. (2004) & $1,329-2,270$ & NA & $0.77-1.45$ & $\begin{array}{l}\text { Normal and } \\
\text { Lightweight }\end{array}$ \\
\hline $\begin{array}{l}\text { Topçu and Uygunoğlu } \\
\text { (2007) }\end{array}$ & $880 *-1,500$ & $3 *-9 *$ & $0.13-0.52$ & Lightweight \\
\hline Gül et al. (2007) & $1,773-1,984$ & $11.3-25.1$ & $0.81-1.22$ & Lightweight \\
\hline Mounanga et al. (2008) & $728-2,109$ & $1.4-24.3$ & $0.22-1.49$ & Lightweight \\
\hline Tandiroglu (2010) & $1,798-1,883$ & $60-80$ & $1.46^{*}-1.76^{*}$ & Lightweight \\
\hline Sengul et al. (2011) & $392-1,937$ & $0.1-28.8$ & $0.13-0.6$ & Lightweight \\
\hline Kim et al. (2012) & $1200 *-2,350 *$ & $9 *-40 *$ & $0.32 *-0.72 *$ & $\begin{array}{l}\text { Normal and } \\
\text { Lightweight }\end{array}$ \\
\hline Wang and Meyer (2012) & $1560-1980$ & $18 *-36.5^{*}$ & $0.27-0.61$ & Lightweight \\
\hline Huang et al. (2013) & $1649-2001$ & $23.33^{*}-48 *$ & $0.29-0.37$ & Lightweight \\
\hline Yu et al. (2013) & $1280-1490$ & $23.3-27.5$ & $0.49-0.85$ & Lightweight \\
\hline Gao et al. (2014) & $950 *-2,063 *$ & $\begin{array}{l}7.67 *- \\
62.78^{*}\end{array}$ & $0.23 *-1.97 *$ & $\begin{array}{l}\text { Normal and } \\
\text { Lightweight }\end{array}$ \\
\hline Yun et al. (2013) & $17,44-2,370$ & $23-43.9$ & $1.30 *-2.25 *$ & $\begin{array}{l}\text { Normal and } \\
\text { Lightweight }\end{array}$ \\
\hline
\end{tabular}

*Extracted from graphs

These studies find that lower density concrete has a lower thermal conductivity, so modern concrete such as Lightweight and Ultra-lightweight concrete has better thermal buffering than traditional concrete (Normal weight concrete), as shown in Figure 1.

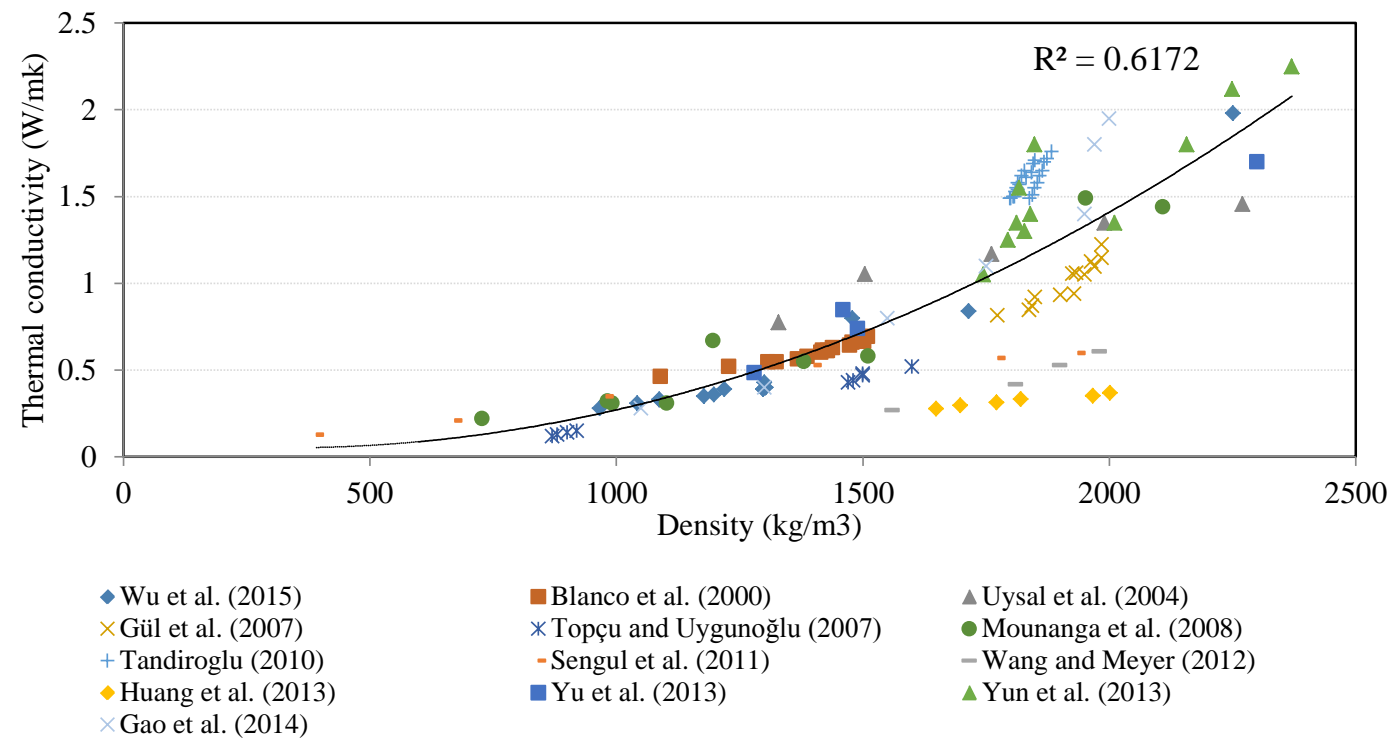

Figure 1 Relationship between thermal conductivity and density 
Several other studies have shown that buildings with a high thermal mass require more time to heat up and cool down, which might influence thermal comfort and demand more energy for heating and cooling $[16,17]$. A number of researchers have also indicated the importance of type and placement of construction materials which alter the thermal capacitance of buildings after refurbishment [18, 19].

Moreover, the ongoing development of more novel construction materials such as Ultra-lightweight concrete $[17,20,21]$ raises a question about their potential impact on the thermal mass of a building and hence on the overall energy performance of a real building during its operational phase.

Therefore, the main objective of this paper is to present the underlying approach and results of the first simulation-based assessment that Ultra-lightweight concrete has on the energy performance and indoor comfort of commercial and residential buildings. This means the primary objective of this study is to indicate how the selection of concrete as a construction material affects the overall energy performance of a building. This study explores a benchmarking method to evaluate the potential effects of conventional (Normal weight) and novel concrete materials (Ultralightweight) on thermal performance of typical office buildings in Australia. A benchmark building serves as a framework to compare design alternatives in terms of their energy performance. The benchmarking system in this study considers the different climate zones in Australia, the forms of construction (Flat and Waffle slabs), and the structural materials (conventional and novel types of concrete).

This research is organised as follows. Section 2 summarises the method used to design the structure and simulate the thermal performance of the benchmark office building. Section 3.1 provides the structural design and analysis results; Sections 3.2 
and 3.3 compare the results of the energy performance of different structural materials and slab types; and Section 4 reports the key findings of this study.

\section{Methodology}

\subsection{Description of Base building}

3 This study assesses the thermal performance of concrete materials (Normal weight and Ultra-lightweight concrete) and structural forms (lightweight and heavyweight) for a benchmark office building in Australia. This 15 storey office building is one of four benchmarking buildings proposed by the National Standard Organization (NSDO) in Australia [22]; This particular15 storey office building is a typical concrete structure [22], with a square plan shape, a total floor area of $1000 \mathrm{~m}^{2}$, and an average $3.3 \mathrm{~m}$ height per storey, as shown in Table 2.

Table 2 Overall specifications of the benchmark building

\begin{tabular}{ccc}
\hline Parameter & Unit & Specification \\
\hline Basement dimensions & $\mathrm{m}$ & $31.62 \times 31.62$ \\
Number of Stories & --- & 15 \\
Concrete slab on ground & $\mathrm{mm}$ & 200 \\
Concrete suspended slab & $\mathrm{mm}$ & 175 \\
Average elevation per floor & $\mathrm{m}$ & 3.3 \\
Verandas) & $\mathrm{m}^{2}$ & 15,000 \\
Total floor Area (including parking, Stairs \& & $\mathrm{m}^{2}$ & $8,807.1$ \\
Total habitable area (external dimensions) & $\mathrm{m}^{2}$ & 962.4 \\
Total habitable area (internal dimensions) & $\mathrm{m}^{2}$ & 11 \\
No of floors above ground level & -- & 176 \\
No of rooms & --- &
\end{tabular}

This building has two parts; the first three underground storeys are parking and storage areas, while the remaining twelve storeys are open plan office areas. The building has non-opening windows, with a base thermal transmittance (U value) of $5.7 \mathrm{~W} / \mathrm{m}^{2} \mathrm{~K}$ and a Solar Heat Gain Coefficient of 0.6 [23]. A sketch of this office building is shown in Figures 2 and 3. 


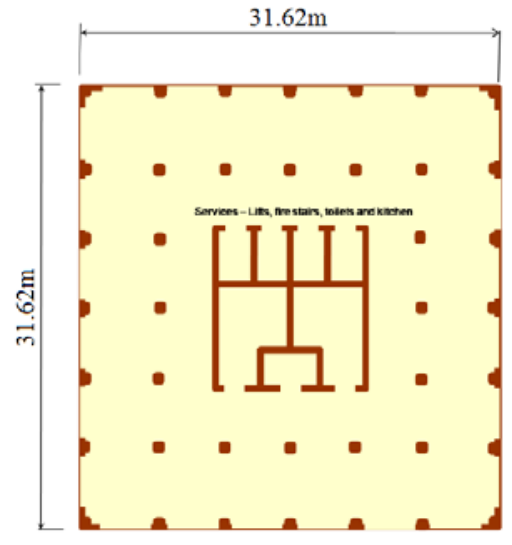

Figure 2 Plan of case study building [22]

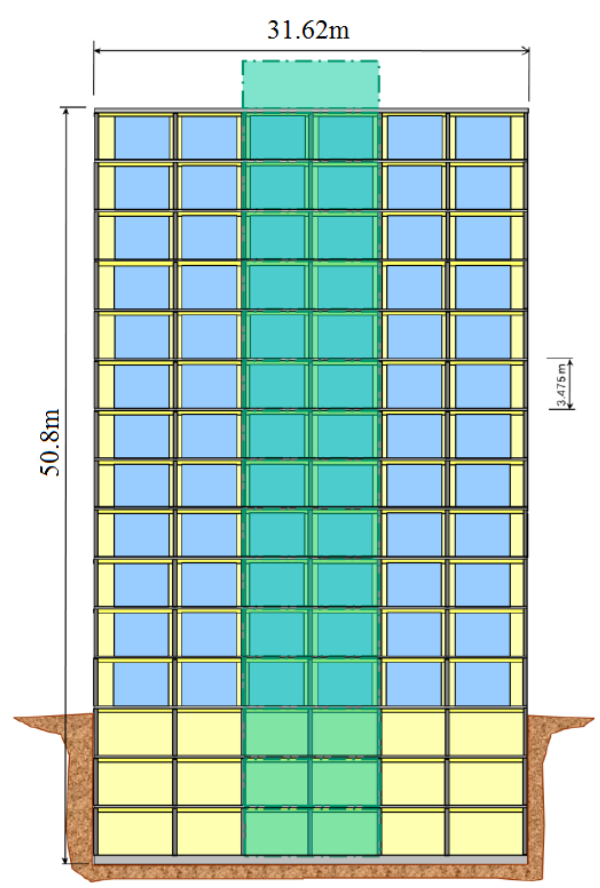

Figure 3 Section view of case study building [22]

\subsection{Structural design parameters}

In terms of structural analysis and design, a concrete structure design is considered to account for lightweight and heavyweight structures if they follow the Australian Standards Concrete structures [24]; the lightweight structure is designed as a Waffle slab and the heavyweight structure as a Flat slab. Flat slabs are very adaptable elements that are generally used to provide minimum depth and flexible column grids in construction, whereas waffle slabs are a lighter and stiffer slab than the equivalent Flat slab. A waffle slab has a thin topping and narrow ribs spanning in both directions between the column heads and/or beam band. The strength and serviceability aspects of the code were utilised during the design of this building. The process for structural analysis is summarised in Figure 4. 


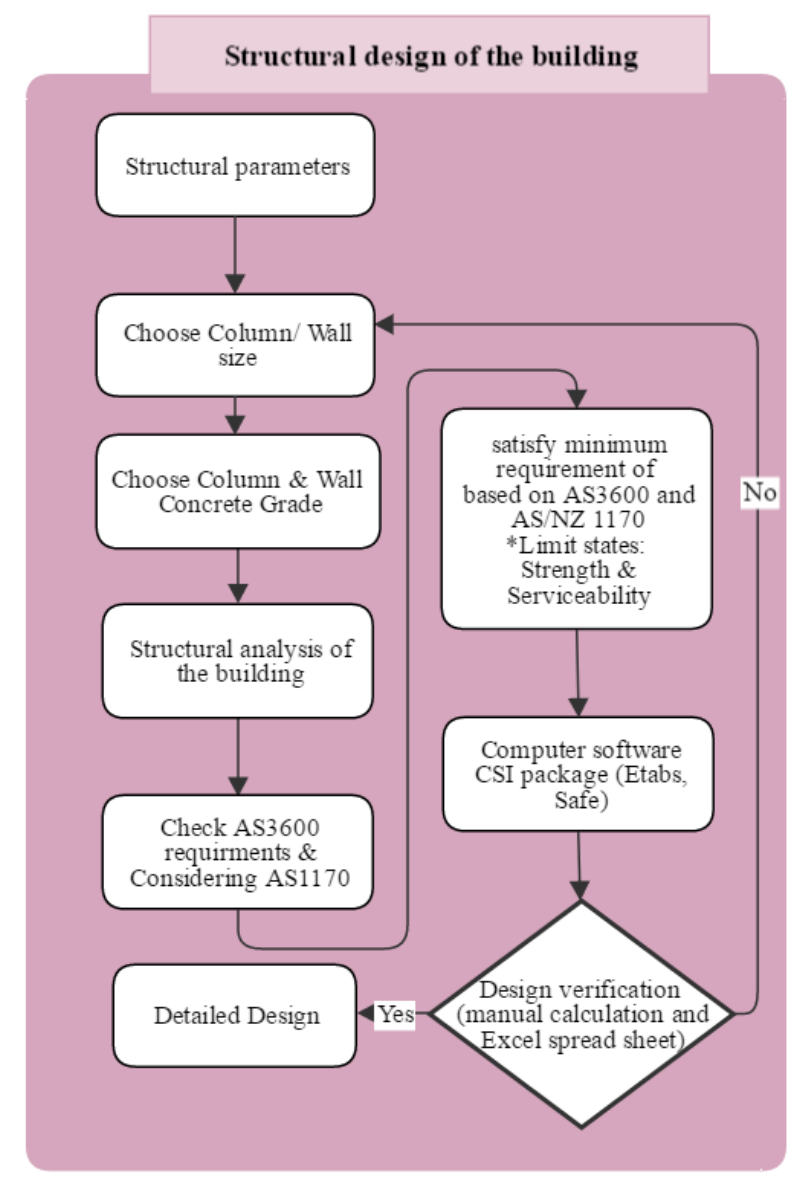

\section{Figure 4 Structural analysis \& design flow}

The amount of live load comes from the Australian and New Zealand Standard for imposed actions [25]. The live load for the office storage and parking areas was 5kPa and 3kPa for the work rooms. The dead load for concrete elements (columns, shear walls, slabs and staircase) was obtained by multiplying the volume of the member by the unit weight of concrete. Wind loads on the building were determined in accordance with Australian and New Zealand standard wind actions [26]. The magnitude of wind pressure on the structure was calculated based on its height above ground, its size, importance, and location. The level of importance is level 3, because the consequence of failure is deemed to be high (based on occupancy and by using AS 1170 [25]). For ultimate limit states and structural serviceability, the annual probability exceedance comes from AS 1170 [25], table 3.1 for a design working life 
of 50 years in a cyclone zone in Australia. To calculate the wind load, zone D was considered to be enough strength in the structure as well as validating the practicality of building in other zones. With the loading conditions, a combination of action loads were used to check the serviceability and strength of the building in accordance with clause 4.2.1 and 4.2.2 of the AS1170 [25], as shown in Table 3. The Computer Aid Design package Etabs, Safe and Microsoft Excel spreadsheet were used to verify the minimum requirements of the concrete design code. The summary of structural analysis is shown in Appendix A.

Table 3 Loading conditions for design the building

\begin{tabular}{|c|c|c|}
\hline \multicolumn{2}{|c|}{ Type of load } & $\begin{array}{r}\text { Load } \\
(\mathrm{kPa}) \\
\end{array}$ \\
\hline \multicolumn{2}{|c|}{ Live load-Office storage and parking area } & 5 \\
\hline \multicolumn{2}{|c|}{ Live load-Work rooms } & 3 \\
\hline \multicolumn{2}{|c|}{ Dead Load } & 4.3 \\
\hline \multirow{2}{*}{ Wind Load- Windward } & Ultimate limit states & 6.6 \\
\hline & Serviceability limit states & 5.4 \\
\hline \multirow{2}{*}{ Wind Load- Leeward } & Ultimate limit states & 4.1 \\
\hline & Serviceability limit states & 3.4 \\
\hline \multirow{2}{*}{ Wind Load- Sidewall } & Ultimate limit states & 1.3 \\
\hline & Serviceability limit states & 1.1 \\
\hline $\begin{array}{l}\text { Load combinations for } \\
\text { Ultimate state design }\end{array}$ & \multicolumn{2}{|c|}{$\begin{array}{c}\text { Load combinations for } \\
\text { serviceability state design }\end{array}$} \\
\hline $\begin{array}{c}1.35 \mathrm{G} \\
1.25 \mathrm{G}+1.5 \mathrm{Q} \\
1.25 \mathrm{G}+1.5 \Psi 1 \mathrm{Q} \\
1.2 \mathrm{G}+\mathrm{Wu}+\Psi \mathrm{cQ} \\
0.9 \mathrm{G}+\mathrm{Wu}\end{array}$ & \multicolumn{2}{|l|}{$\begin{array}{c}\mathrm{G}+\Psi 1 \mathrm{Q} \\
\mathrm{G}+\Psi \mathrm{s} Q \\
\mathrm{G}+\Psi \mathrm{sQ}+\mathrm{Ws}\end{array}$} \\
\hline \multicolumn{3}{|c|}{ 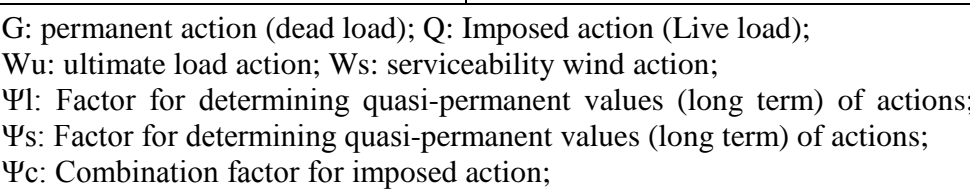 } \\
\hline
\end{tabular}

\subsection{Structural materials}

This study analyses the effects choices of concrete (normal and low-density) have on the thermal performance of a heavyweight and lightweight office structure. For the purpose of this study, the types of concrete mixes were collected from previously published journal papers and databases [3, 4, 11, 15]. These designs represent 
conventional (Normal weight) and some advanced methods of concrete admixture that give Ultra-lightweight concrete. Table 4 summarises the properties and grade of the concrete analysed in this paper. Novel forms of concrete admixture (such as Ultra-lightweight) are included in this paper to point out their potential effects on the thermal behaviour of the building; they have not yet been covered in the mainstream of previous studies.

Table 4 Properties of selected concrete

\begin{tabular}{lccccc}
\hline \multicolumn{1}{c}{ Type of Concrete } & $\begin{array}{c}\text { Grade } \\
(\mathrm{MPa})\end{array}$ & $\begin{array}{c}\text { Density } \\
\left(\mathrm{Kg} / \mathrm{m}^{3}\right)\end{array}$ & $\begin{array}{c}\text { Thermal } \\
\text { conductivity } \\
(\mathrm{W} / \mathrm{mK})\end{array}$ & $\begin{array}{c}\text { Specific } \\
\text { heat } \\
\mathrm{kJ} /(\mathrm{kg} . \mathrm{k})\end{array}$ & Source \\
\hline N40- Normal weight $^{1}$ & 40 & 2393 & 1.96 & 0.88 & {$[11]$} \\
N40- Ultra-lightweight $^{1}$ & 40 & 1400 & 0.31 & 0.88 & [3] \\
N32- Normal weight $^{2}$ & 32 & 2470 & 2.10 & 0.88 & {$[15]$} \\
N32- Ultra-lightweight $^{2}$ & 32 & 1164 & 0.28 & 0.88 & [3] \\
N20- Normal weight $^{3}$ & 20 & 1483 & 1.38 & 0.88 & [4] \\
\hline
\end{tabular}

1. Grade N40 used in the vertical structural elements such as columns and shear walls.

2. Grade N32 used in the slabs (Waffle and Flat).

3. Grade N20 used in the other concrete element (staircase).

\subsection{Operational energy analysis}

Heavyweight (Flat) and lightweight (Waffle slab) structures were modelled and compared for their impact on the energy performance of the building by using the DesignBuilder energy simulation software. DesignBuilder is a user interface for the EnergyPlus dynamic thermal simulation engine and requires hourly weather data as inputs. The weather data used for each city in this study was extracted from the EnergyPlus weather database [27]. The weather data are in RMY format, they are a set of weather files developed to comply with the Building Code of Australia [27].

The equipment and occupancy schedules were extracted from the Building Code of Australia [28]. The schedules assume $10 \%$ of office equipment and $10 \%$ of lights remain on during unoccupied hours. The HVAC system was modelled using a variable air volume system (VAV) with the autosize routine in DesignBuilder's 
“simple” HVAC description [29]. Table 5 summarises the main assumptions used for the simulations.

Table 5 Simulated assumptions for benchmark building

\begin{tabular}{ccc}
\hline Parameters & Key variables & References \\
\hline Lighting power density & $9\left(\mathrm{~W} / \mathrm{m}^{2}\right)$ & {$[28]$} \\
Occupancy density & $10\left(\mathrm{~m}^{2} /\right.$ person $)$ & {$[28]$} \\
Equipment load & $15\left(\mathrm{~W} / \mathrm{m}^{2}\right)$ & {$[28]$} \\
Domestic hot water & $0.4\left(\mathrm{~L} / \mathrm{m}^{2}\right)$ & {$[28]$} \\
Infiltration & $0.28(\mathrm{ACH})$ & {$[30]$} \\
Ventilation requirements & $10(\mathrm{~L} / \mathrm{s} /$ person $)$ & {$[28]$} \\
HVAC set point & $18^{\circ} \mathrm{C}$ (heating) & {$[28]$} \\
\hline
\end{tabular}

*The schedules were extracted from Building Code of Australia [28]

This study used the Building Code of Australia (BCA) "deemed to satisfy" approach to define the envelope construction of the modelled building (as shown in Table 6). To understand the relative magnitude of the change in predicting energy consumption due to changes in the form of construction and type of structural concrete, the office building was modelled in four different ways: 1) as a Flat slab with Normal weight; 2) as a Flat slab with Ultra-lightweight concrete; 3) a Waffle slab with Normal weight concrete; and 4) a Waffle slab with Ultra-lightweight concrete. The vertical elements (columns and shear walls) consist of concrete with grade N40, the slabs (Waffle and Flat) contain N32 and the other elements (staircase) are made of N20. The modelling results for all four buildings revealed the total energy usage as well as the heating and cooling loads across different input parameters (design alternatives). The total energy consumption was compared to national and state averages determined from real world data from Australian office buildings to ensure the results are within reasonable ranges of the published and predicted energy consumption values [31]. 
Table 6 Physical properties of benchmark building

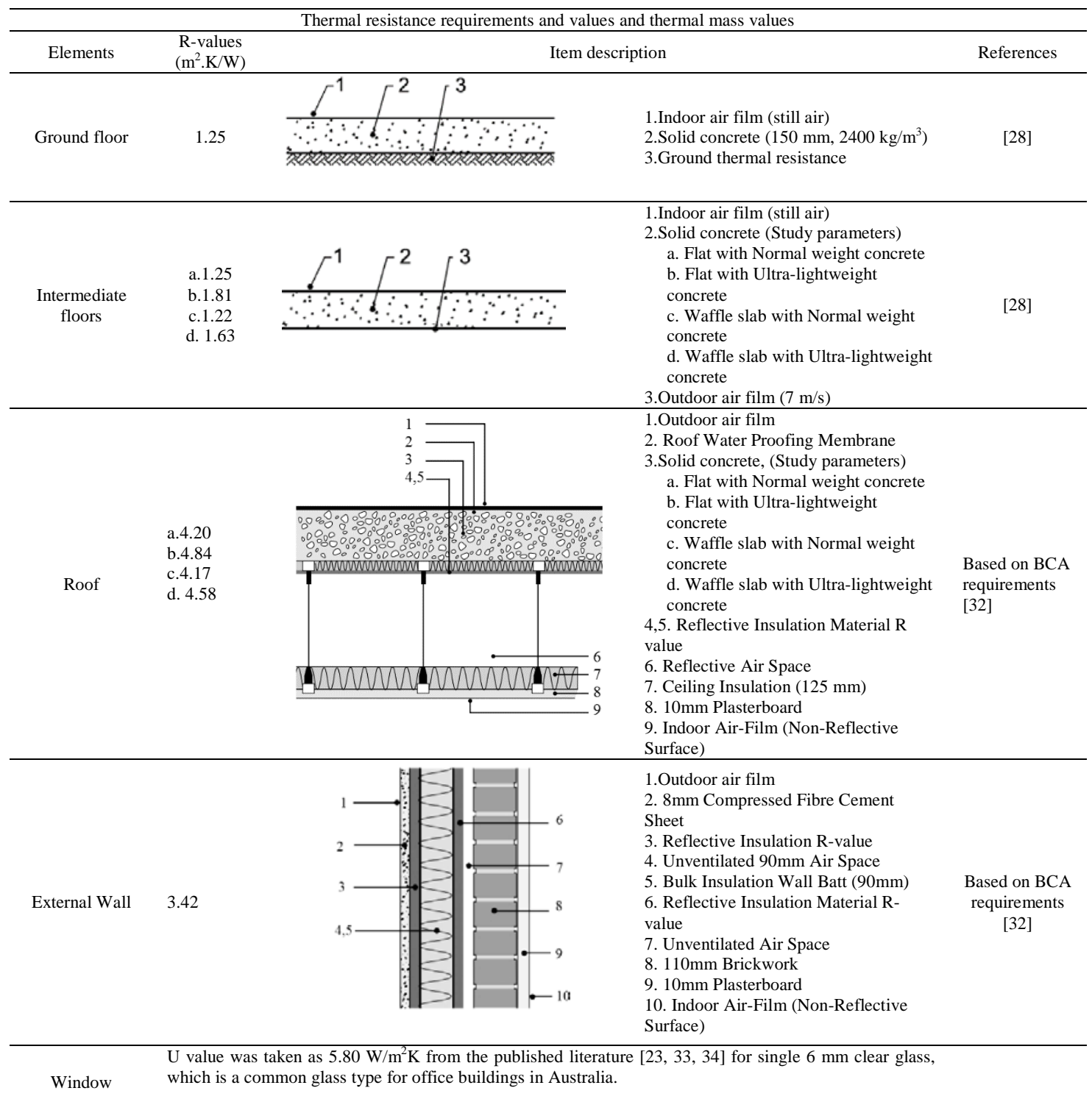

\section{Results and discussion}

\subsection{Structural analysis and design}

The office benchmark building has been structurally designed based on Australian Standards in order to verify whether it can be used for realistic comparisons. The structural design specified heavyweight and lightweight alternatives for the Flat slab and Waffle slab construction. The structural analysis and design quantified the minimum size of the slab and column for each form of construction. The columns were classified into five (5) different groups based on their cross section and 
reinforcement details (Appendix A). The columns at the lower level have a larger cross sectional area and a higher ratio of steel than the upper columns. The dynamic lateral forces (earthquake) are excluded from the scope of this study because the wind pressure loads are much more critical than earthquakes in most parts of Australia. The structural design is summarised in Table 7 (the structural design is shown in Appendix A).

Table 7 Summary of the structural design

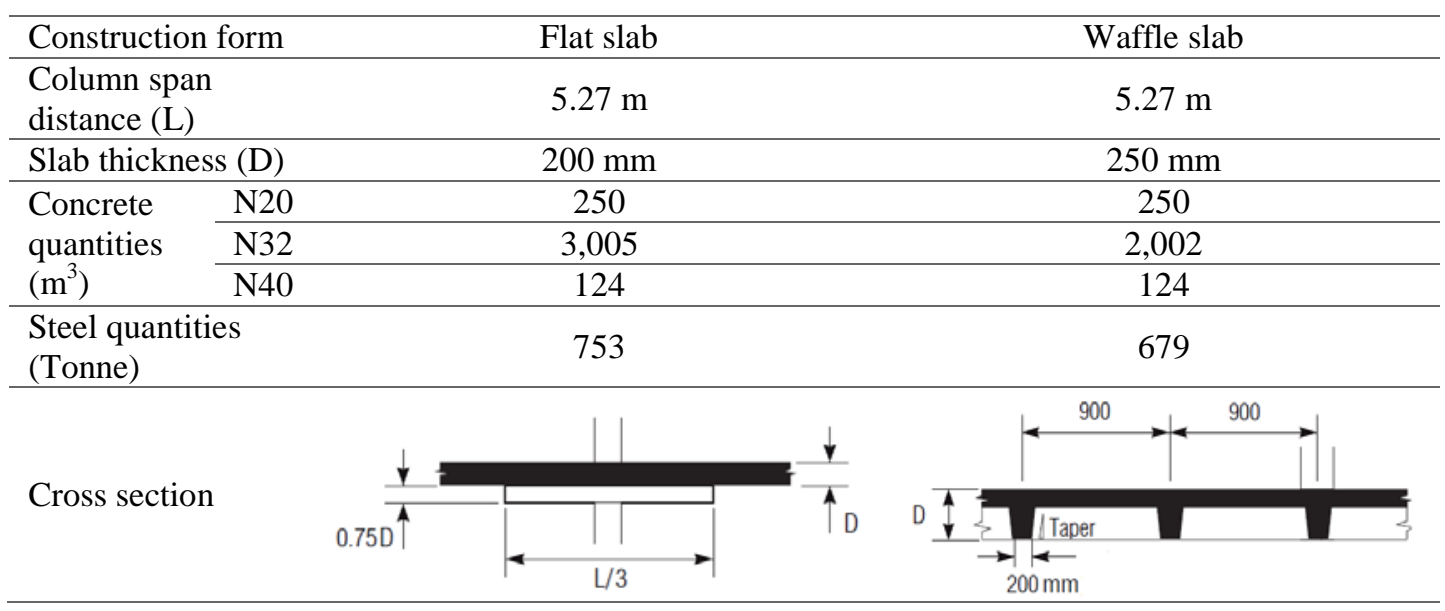

\subsection{Energy performance of the building (Energy consumption)}

Five major locations were selected for five major Australian cities and the heating and cooling hours are shown in Figure 5. The heating and cooling hours are calculated based on the differences between the outside weather temperature and a reference temperature which considered less than 18 degrees Celsius for heating and more than 24 degrees Celsius for cooling [35]. Darwin is located in climate zone 1, so it has a perennially hot climate with the highest number of cooling hours (Hot humid summer \& warm winter). Brisbane has the second highest cooling degree hours and is (climate zone 2) having a subtropical climate with warm, humid summers and mild winters. Sydney's climate is influenced by abundant sunshine over the summer and a mild winter (climate zone 5) that results in higher heating 
degree hours than Brisbane. Melbourne and Canberra have high heating demand compared to the other cities. Melbourne has a temperate climate with changeable weather conditions in the spring and summer seasons (climate zone 6). Canberra is a cool temperate climate zone, with the highest heating degree hours over a year of the five climates examined in this study.

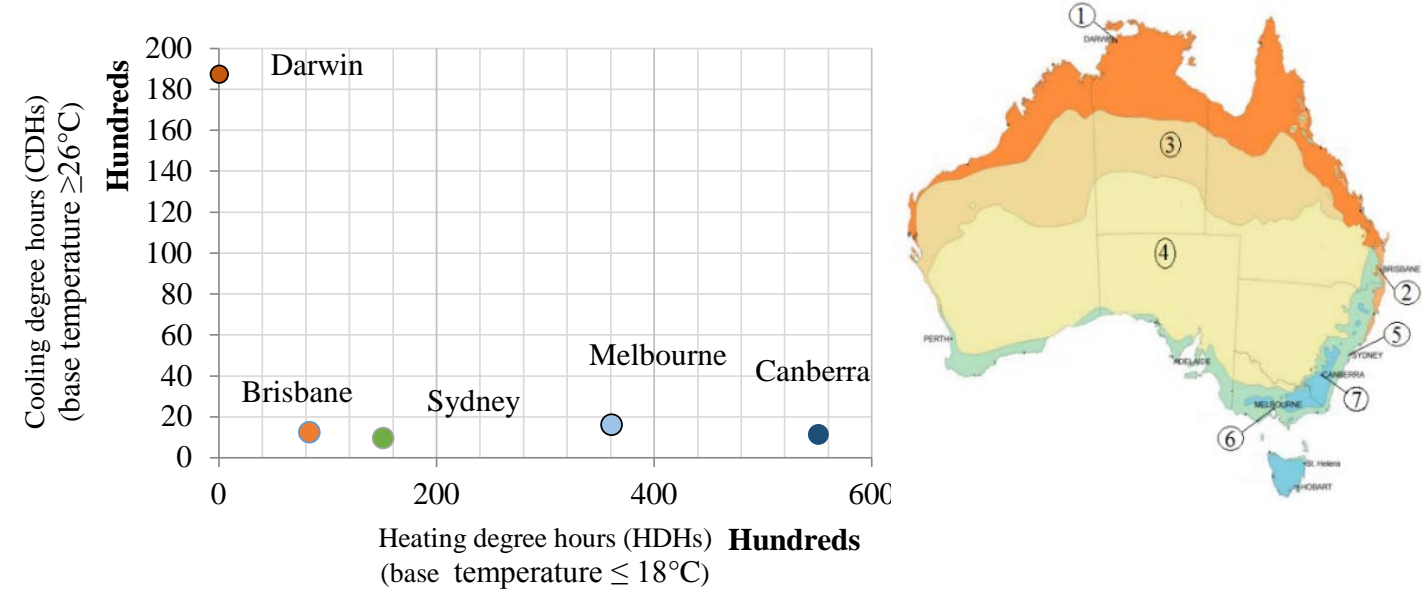

Climate zones: Darwin (1); Brisbane (2); Sydney (5); Melbourne (6); Canberra (7)

\section{Figure 5 Summary of the annual heating and cooling degree-hours}

The simulated annual energy consumption compared with the average national energy usage across the five major climate zones is shown in Figure 6. The Australian national average for commercial building energy consumption is $272 \pm 17$ [kWh/m²], with a standard deviation of $128\left[\mathrm{kWh} / \mathrm{m}^{2}\right]$ per year $[33,36]$, and the simulated outputs from this study are within these ranges. The results of the simulated building energy performance showed that in this type of highly glazed office buildings, the cooling load is much higher than the heating load across all five climates studied. 

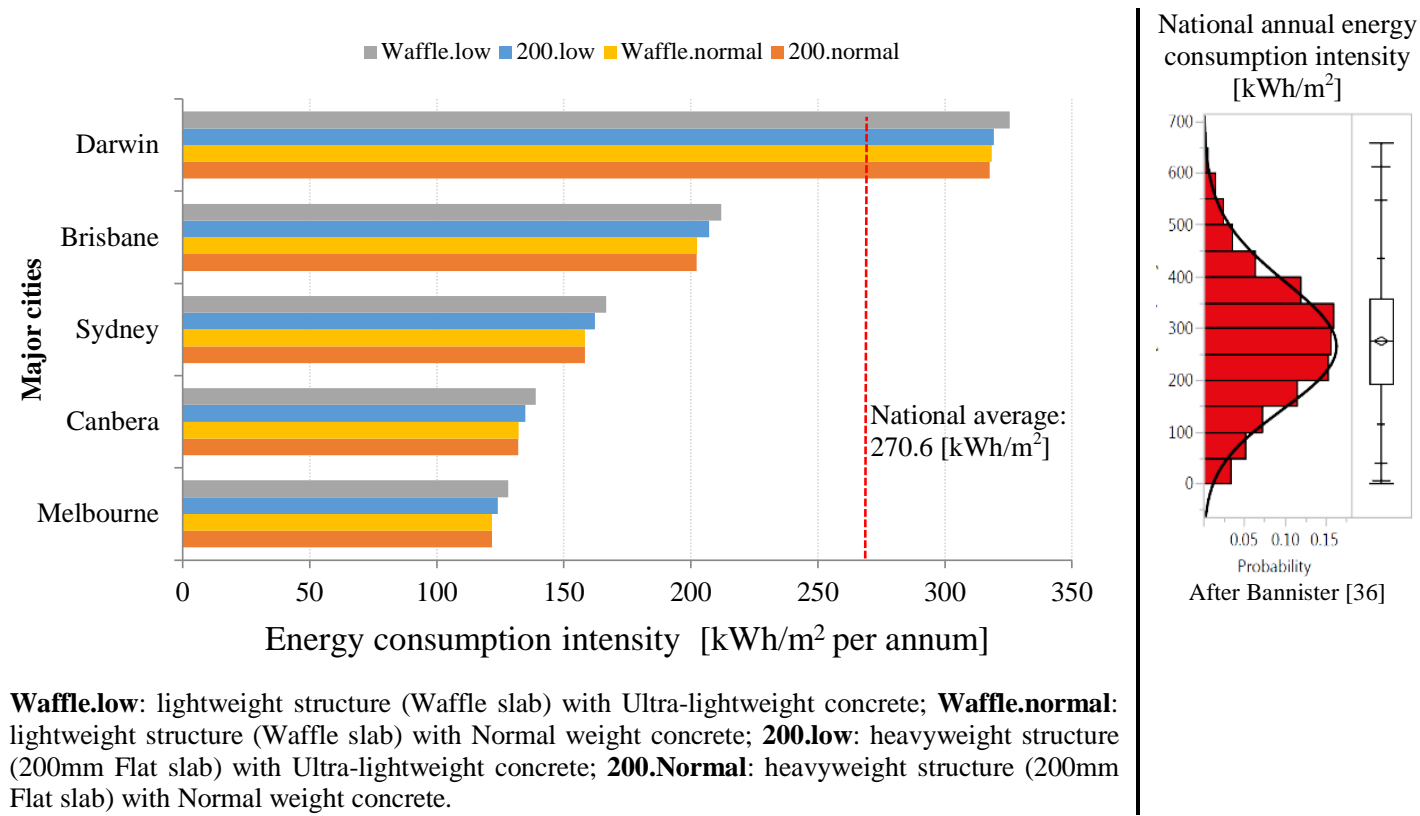

Waffle.low: lightweight structure (Waffle slab) with Ultra-lightweight concrete; Waffle.normal: lightweight structure (Waffle slab) with Normal weight concrete; 200.low: heavyweight structure (200mm Flat slab) with Ultra-lightweight concrete; 200.Normal: heavyweight structure (200mm Flat slab) with Normal weight concrete.

\section{Figure 6 Predicted annual energy consumptions and national energy average usage across five major climate zones}

The energy consumption across all five climates shows that the lightweight office building (called Waffle.low) with a lower thermal conductivity concrete (Ultralightweight concrete) demanded more energy than the other buildings because its fast response to temperature and heat flux excitations causes overheating for most of the year. The energy consumption predicted for the heavier type of office building (Flat slab using Normal weight concrete) was consistently lower than the buildings with Ultra-lightweight concrete (Waffle.low and 200.low). Figure 7 shows a comparison between the cooling energy requirements of the building with different construction (Flat and Waffle slab) and different types of concrete. Note that the cooling energy requirements of the buildings were affected by the quantity (lightweight and heavyweight structure) and type of concrete (Normal weight and Ultra-lightweight) used in the building. Ultra-lightweight concrete had a great effect on the demand for cooling energy in colder climates; for example, the lightweight office building (Waffle slab) with Ultra-lightweight concrete in Melbourne required up to 14\% more 
cooling energy than the heavyweight structure (Flat slab) with Normal weight concrete.

When Normal weight concrete was used there was not a noticeable difference of the demand for cooling energy between buildings with heavyweight and lightweight structures. However, the simulations for the building with Ultra-lightweight concrete showed that the cooling energy needed by the heavyweight structure (200.low - Flat slab) was less than the lightweight structure (Waffle.low - Waffle slab) across all five climates, albeit the differences were only between $2-3 \mathrm{kWh} / \mathrm{m}^{2}$ per annum.
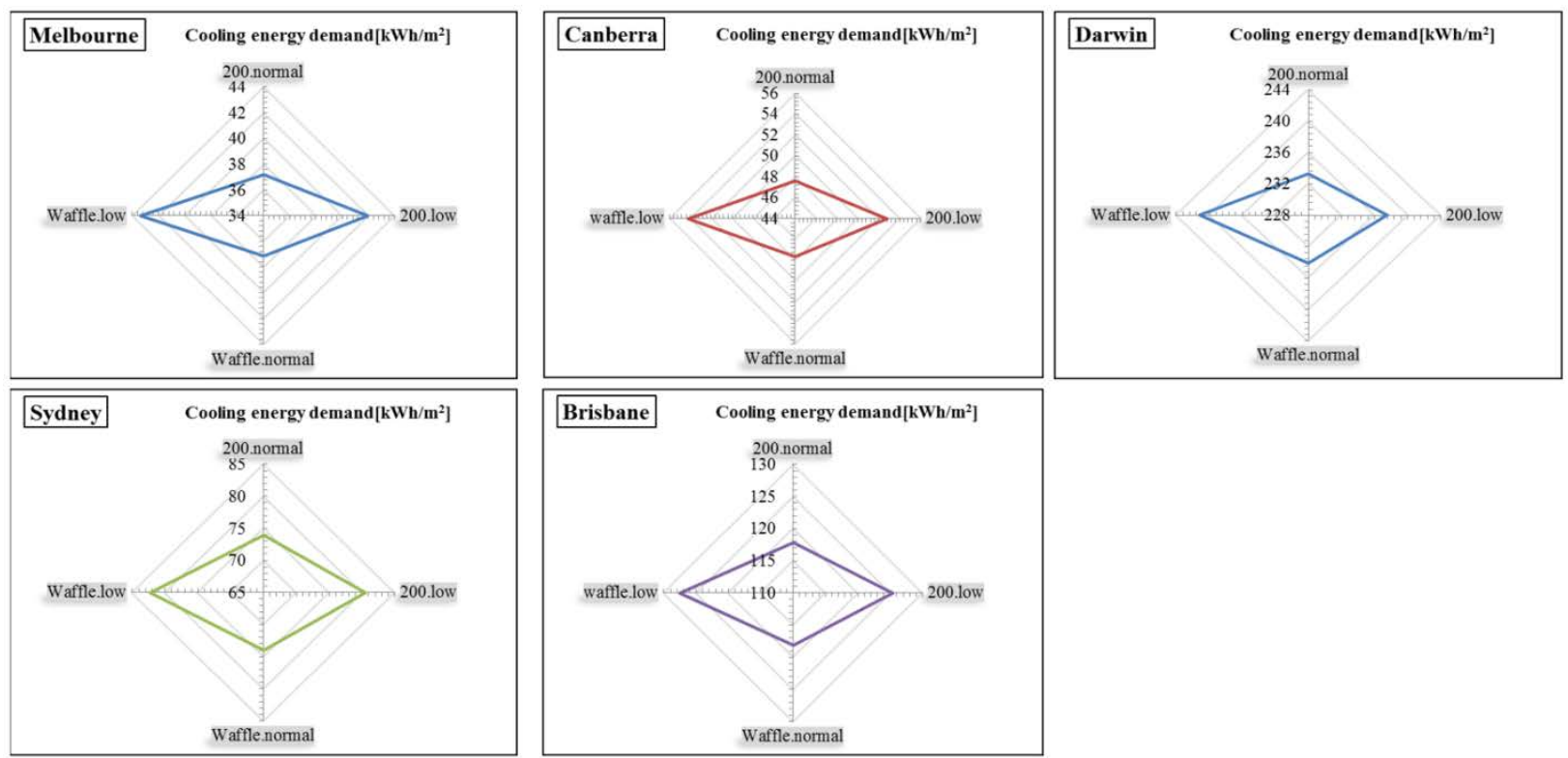

Waffle.low: lightweight structure (Waffle slab) with Ultra-lightweight concrete; Waffle.normal: lightweight structure (Waffle slab) with Normal weight concrete; 200.low: heavyweight structure (200mm Flat slab) with Ultra-lightweight concrete; 200.Normal: heavyweight structure (200mm Flat slab) with Normal weight concrete.

Figure 7 Comparison between the annual energy requirements, structural forms and construction materials of the office buildings

\subsection{Analysis of thermal performance}

The results of sub-hourly dynamic simulations were analysed with no active heating/cooling system being used (free-floating conditions) in order to compare the behaviour of the different building models in terms of indoor temperature during the summer and winter seasons. To reduce the quantity of data for this paper, representative periods taken from the set of simulations were analysed with reference 
to winter and summer seasons (as shown in Table 8). In Australia, the summer and winter seasons are defined from December to February (for climate zone 1, the hottest season starts from mid-November) and June to August, respectively.

Table 8 Summer and Winter design weeks for the climate zones [29]

\begin{tabular}{ccc}
\hline City (Climate Zone) & Winter design week & Summer design week \\
\hline Darwin (1) & 10 to 16 Jun & 19 to 25 November \\
Brisbane (2) & 3 to 9 August & 17 to 23 February \\
Sydney (5) & 20 to 26 July & 3 to 9 February \\
Melbourne (6) & 6 to 12 July & 27 January to 2 February \\
Canberra (7) & 8 to 15 July & 1 to 8 January \\
\hline
\end{tabular}

The indoor air temperature simulated hourly for the top floor was plotted against the hourly outdoor temperature to compare the indoor thermal performance across the different types of construction (as shown in Figure 8 and Appendix B). Indoor air temperatures were plotted against outdoor air temperatures for all four types of construction types, and show that those buildings with Normal weight concrete had a lower slope of regression in response to fluctuations in the outdoor air temperature, whereas the buildings with Ultra-lightweight concrete had a higher regression coefficient. 


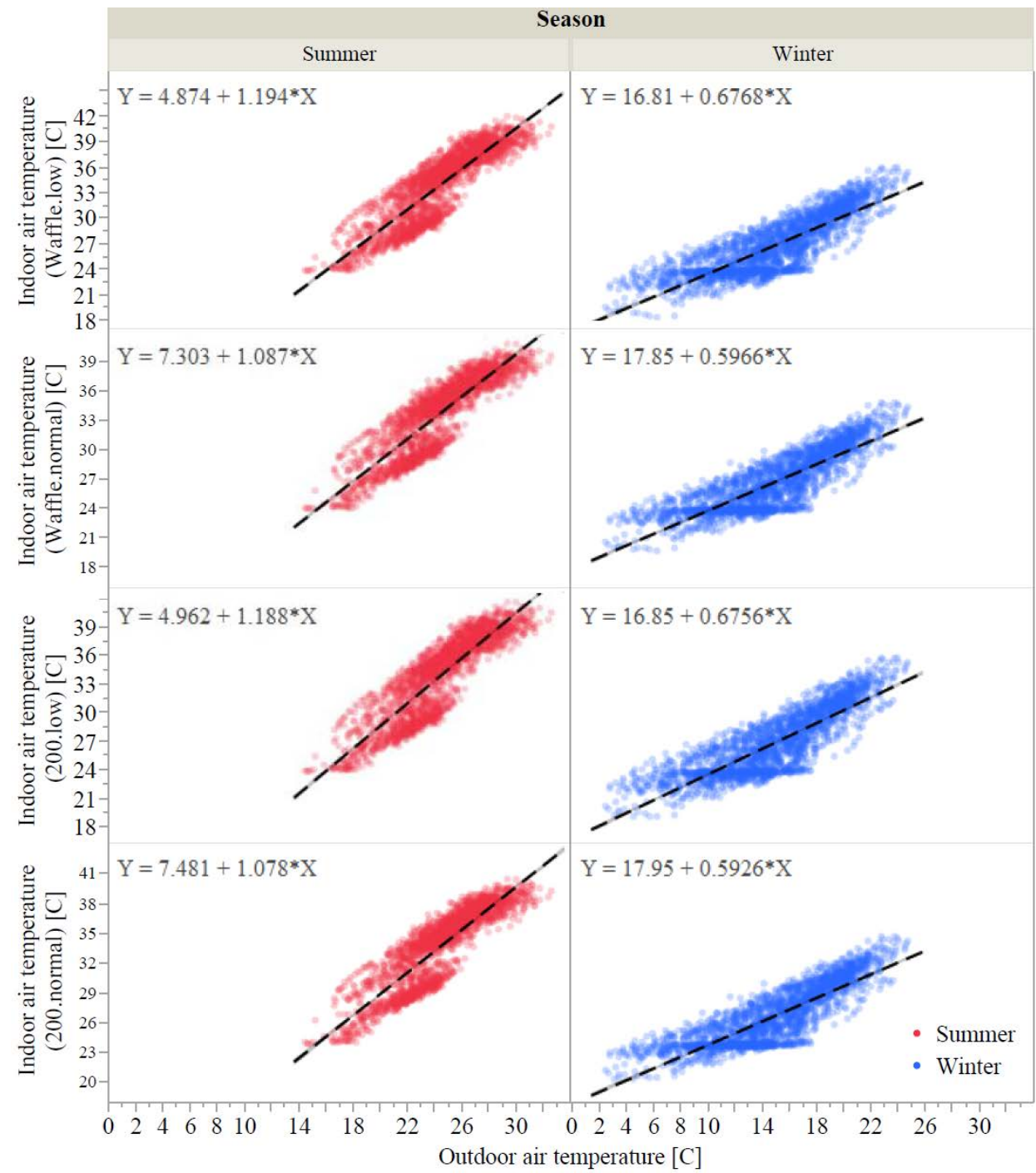

Figure 8 hourly air room temperature plotted against the hourly outdoor temperate for the Waffle.low and 200.normal in the climate zone 2 (Brisbane).

The hourly free floating analysis for the buildings with selected constructions shows how the structural mass and type of concrete affected the daily peak indoor temperatures. Table 9 summarises the differences in the peak daily indoor air temperature between the highest and lowest structural mass and concrete density (200.normal and Waffle.low, respectively). Note that the peak indoor temperatures are higher in those building with Ultra-lightweight concrete and lower structural mass (Waffle.low). For instance, the mean differences in the peak indoor air 
temperature between the Waffle.low and 200.normal cases (both located in climate 2) in summer and winter are 1.1 and $1.0^{\circ} \mathrm{C}$ respectively.

Table 9 Differences in the peak daily indoor air temperature between Waffle.low and 200.normal

\begin{tabular}{|c|c|c|c|c|c|c|c|c|c|}
\hline & \multicolumn{3}{|c|}{ Year } & \multicolumn{3}{|c|}{ Summer season } & \multicolumn{3}{|c|}{ Winter season } \\
\hline & $\begin{array}{c}\text { Annual } \\
\text { mean of } \\
\text { peak daily } \\
\text { indoor air } \\
\text { temperature } \\
\text { difference } \\
{\left[{ }^{\circ} \mathrm{C}\right]}\end{array}$ & 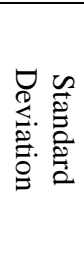 & 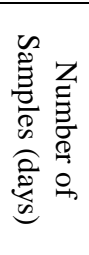 & $\begin{array}{c}\text { Annual } \\
\text { mean of } \\
\text { peak daily } \\
\text { indoor air } \\
\text { temperature } \\
\text { difference } \\
{\left[{ }^{\circ} \mathrm{C}\right]}\end{array}$ & 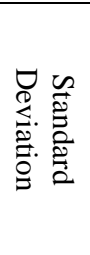 & 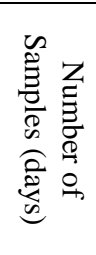 & $\begin{array}{c}\text { Annual } \\
\text { mean of } \\
\text { peak daily } \\
\text { indoor air } \\
\text { temperature } \\
\text { difference } \\
{\left[{ }^{\circ} \mathrm{C}\right]}\end{array}$ & 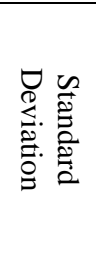 & 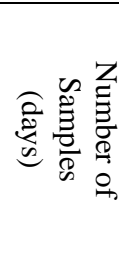 \\
\hline Canberra & 0.9 & 0.64 & 365 & 1.2 & 0.75 & 90 & 0.7 & 0.52 & 90 \\
\hline Melbourne & 0.8 & 0.75 & 365 & 1.3 & 0.88 & 90 & 0.5 & 0.51 & 90 \\
\hline Sydney & 1.0 & 0.75 & 365 & 1.1 & 0.65 & 90 & 0.8 & 0.54 & 90 \\
\hline Brisbane & 1.0 & 0.75 & 365 & 1.1 & 0.46 & 90 & 1.0 & 0.39 & 90 \\
\hline Darwin & 1.0 & 0.75 & 365 & 1.0 & 1.22 & 90 & 1.1 & 0.18 & 90 \\
\hline
\end{tabular}

Figures 9 to 13 show the hourly indoor air temperatures during the summer and winter seasons; note that the building with a lower structural mass (thermal mass) and lower concrete density (Ultra-lightweight) is more sensitive to changes in the outdoor temperatures.

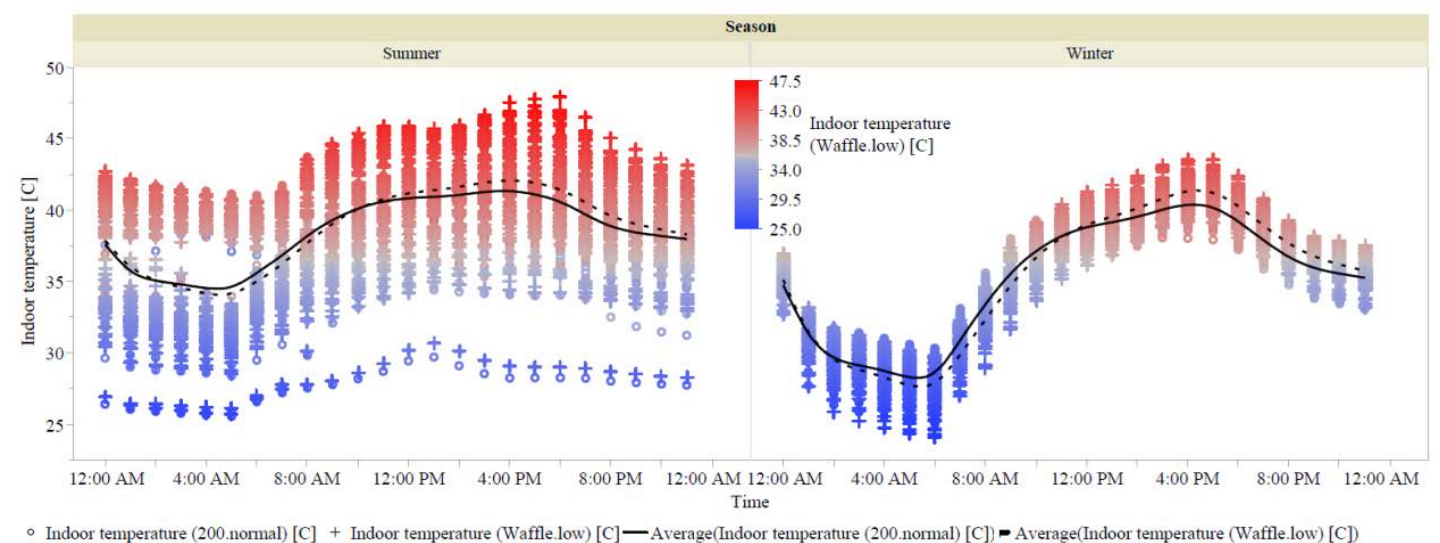

Figure 9 Summer and Winter free floating temperature in climate zone 1 (Darwin) 


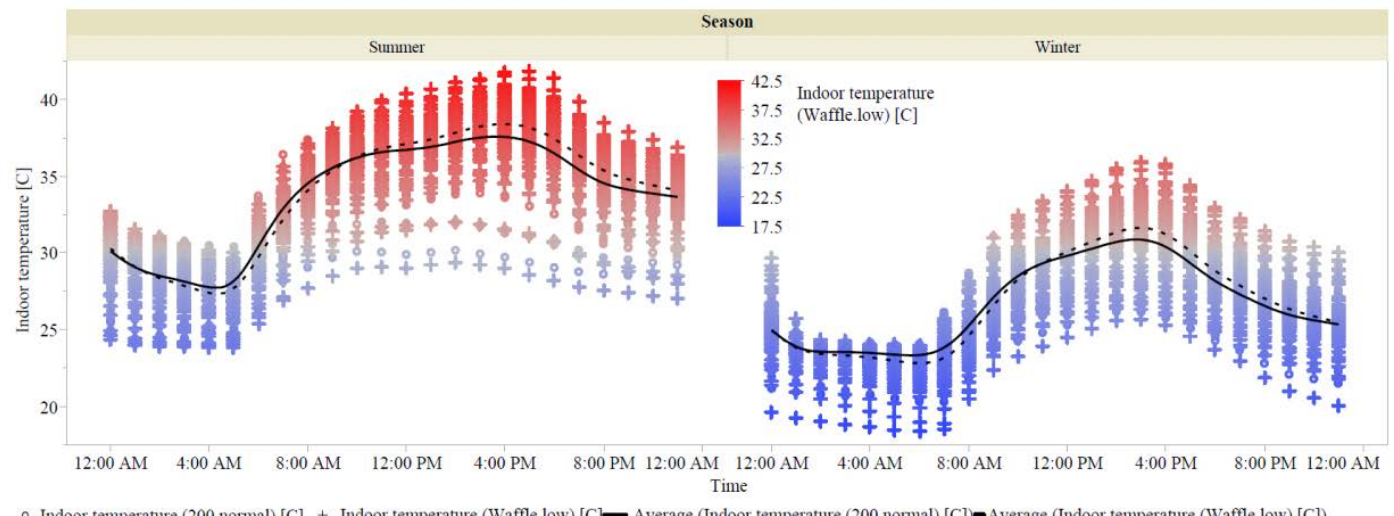

Figure 10 Summer and Winter free floating temperature in climate zone 2 (Brisbane)

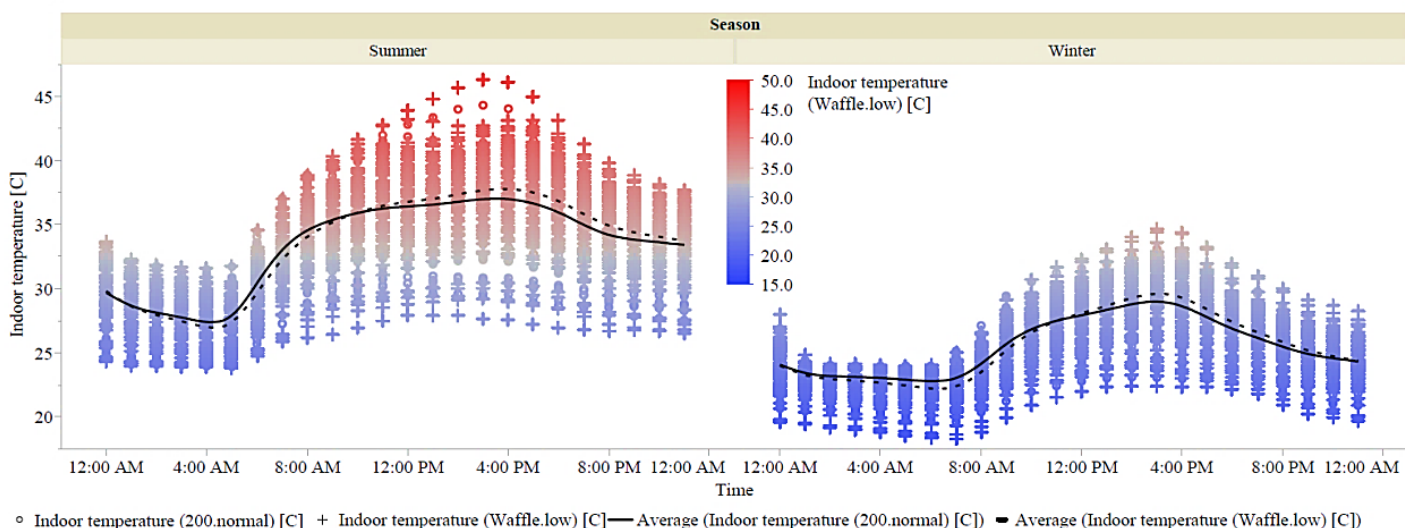

Figure 11 Summer and Winter free floating temperature in climate zone 5 (Sydney)

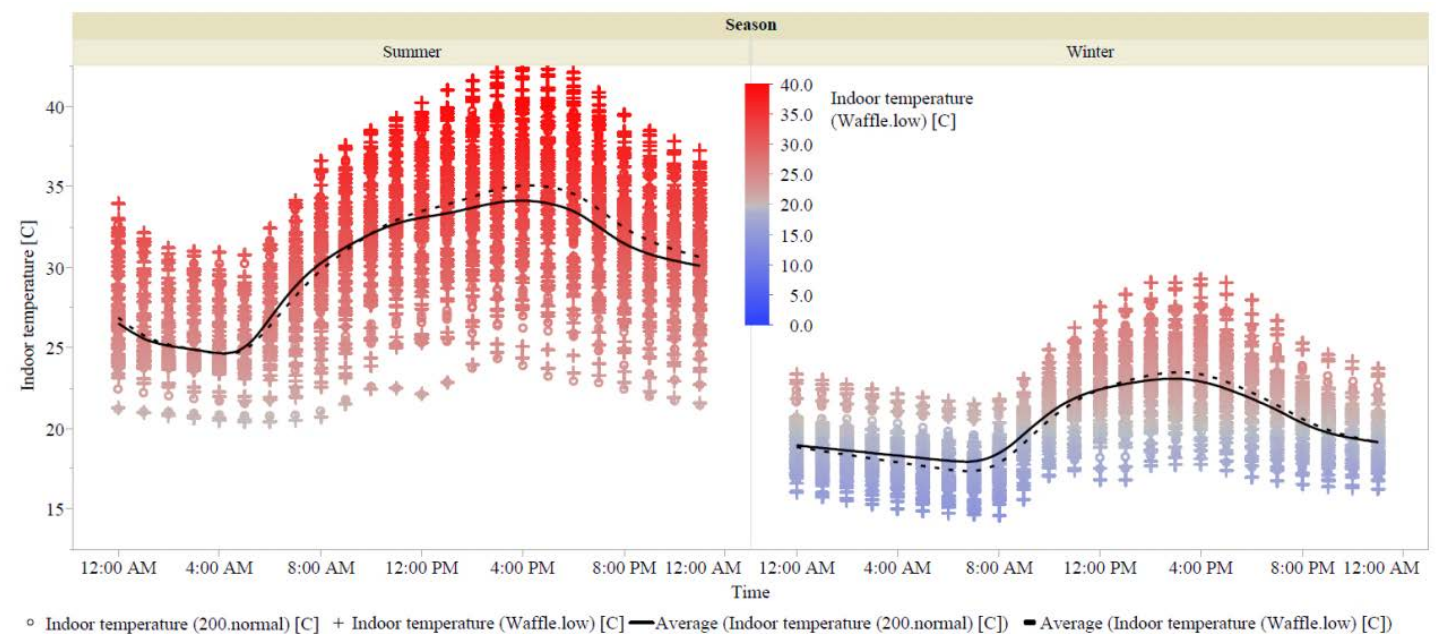

Figure 12 Summer and Winter free floating temperature in climate zone 6 


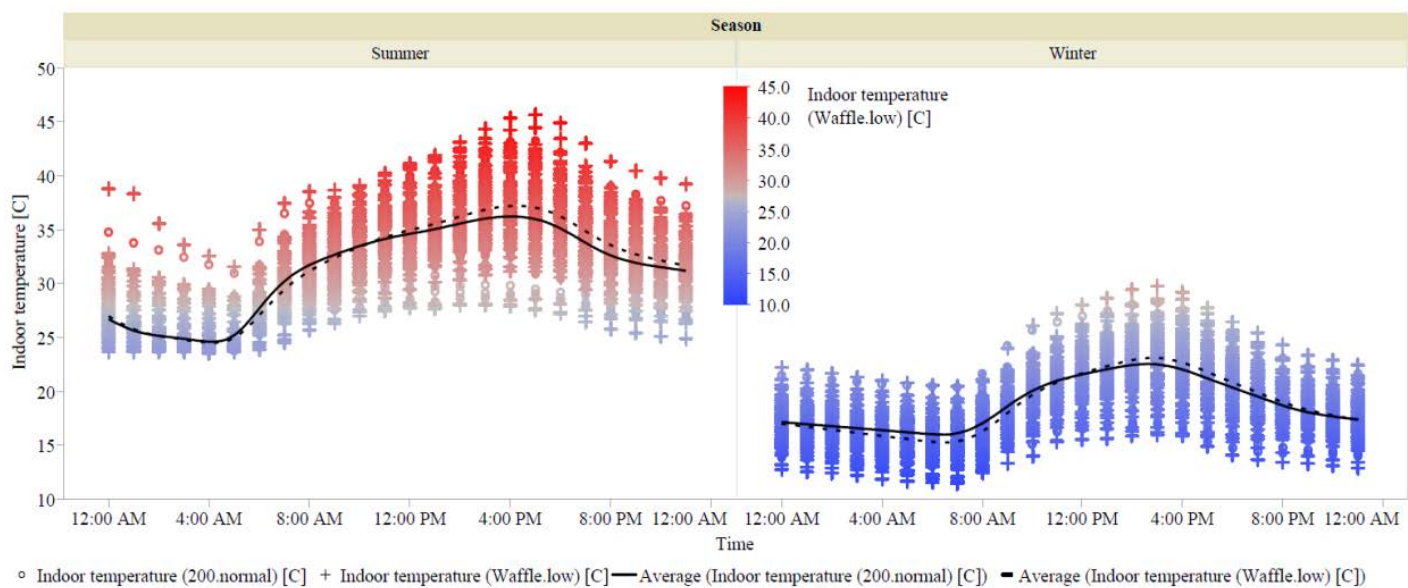

Figure 13 Summer and Winter free floating temperature in climate zone 7 (Canberra)

\subsection{Design week-free floating analysis}

Figure 14 plots the frequency of indoor air temperature during the summer and winter design weeks by considering the heavyweight building with Normal concrete (200.normal) and the lightweight building with Ultra-lightweight concrete (Waffle.low); the indoor air temperature of both buildings and across all climates was outside the desired air set point ranges (18 to $\left.26^{\circ} \mathrm{C}\right)$ most of the time, accompanied by consistent overheating (air temperatures higher than $26^{\circ} \mathrm{C}$ ). 


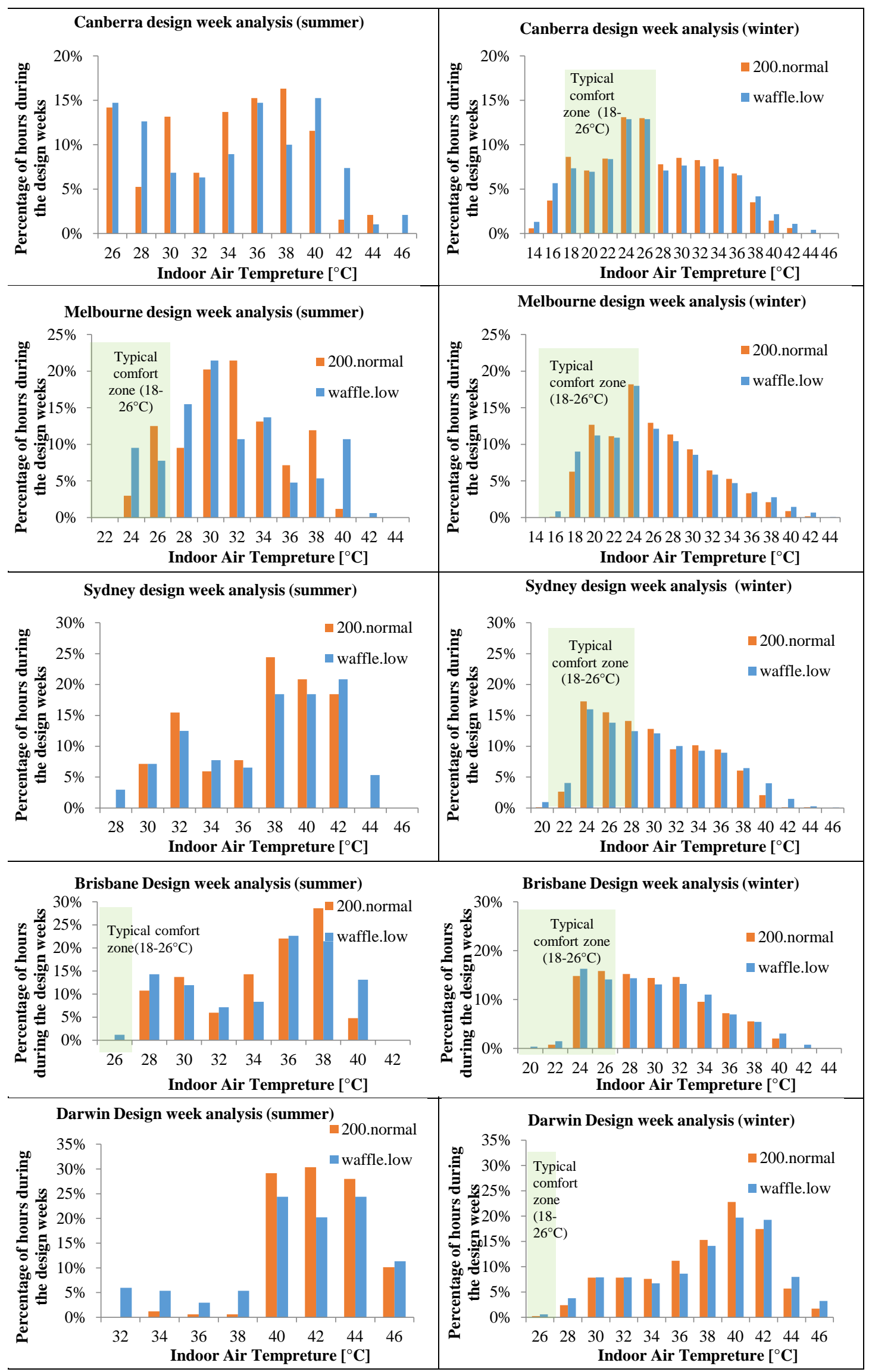

Figure 14 Frequency of occurrence of indoor air temperatures during the summer and winter design weeks for 200 .normal and Waffle.low 
Those structures with higher thermal conductivity concrete (200.normal) had lower peak indoor air temperatures than the low thermal conductivity concrete structures (Waffle.low); for example, the variations of indoor and outdoor air temperature for the designed buildings in two climate zones (1 and 6) during the winter design week are shown in Figure 15. They indicate that the concrete structure with a lower thermal conductivity had a substantial increase of peak indoor air temperature by $1.2^{\circ} \mathrm{C}$ and $2^{\circ} \mathrm{C}$ in hot and cold climate zones, respectively (as shown in Figure 15 and in Appendix C).
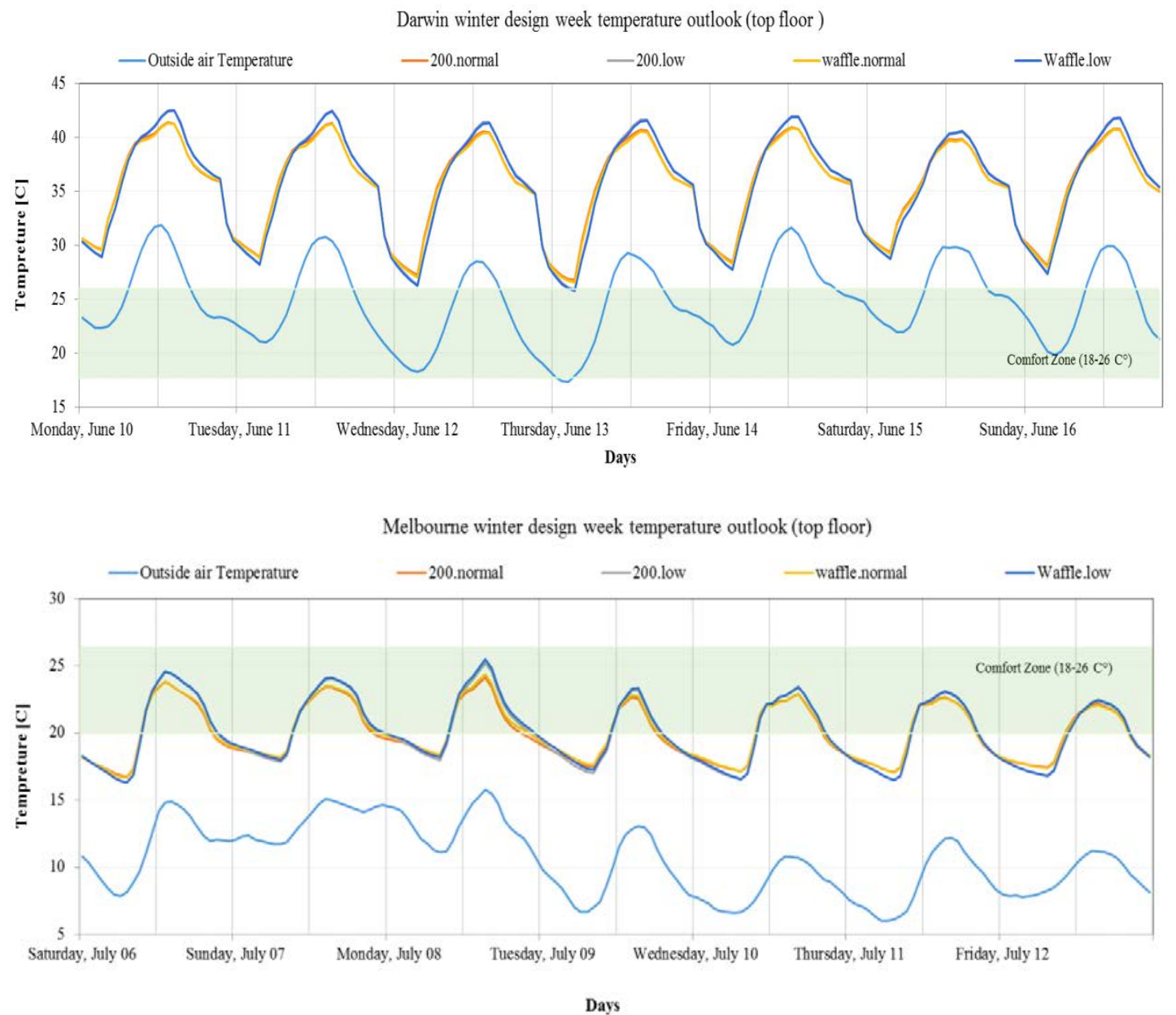

Figure 15 Analysis of Winter design week free-floating for climate zones 1 (Darwin) and 6 (Melbourne) 
In the summer design week, the resulting temperature patterns show that lighter buildings characterised by Ultra-lightweight concrete (Waffle.low) experienced a higher daily oscillation than the other types of construction (as shown in Figure 16 and in Appendix C), where the building with higher mass and Normal weight concrete (200.normal) structures had lower indoor air temperatures in general and a peak indoor air temperature that was $1.6-2.4^{\circ} \mathrm{C}$ lower than the lighter construction types. However, those structures in the hot dominated climate zone (Darwin) built with Ultra-lightweight materials lost heat quickly and cooled down faster during the night than the other buildings.
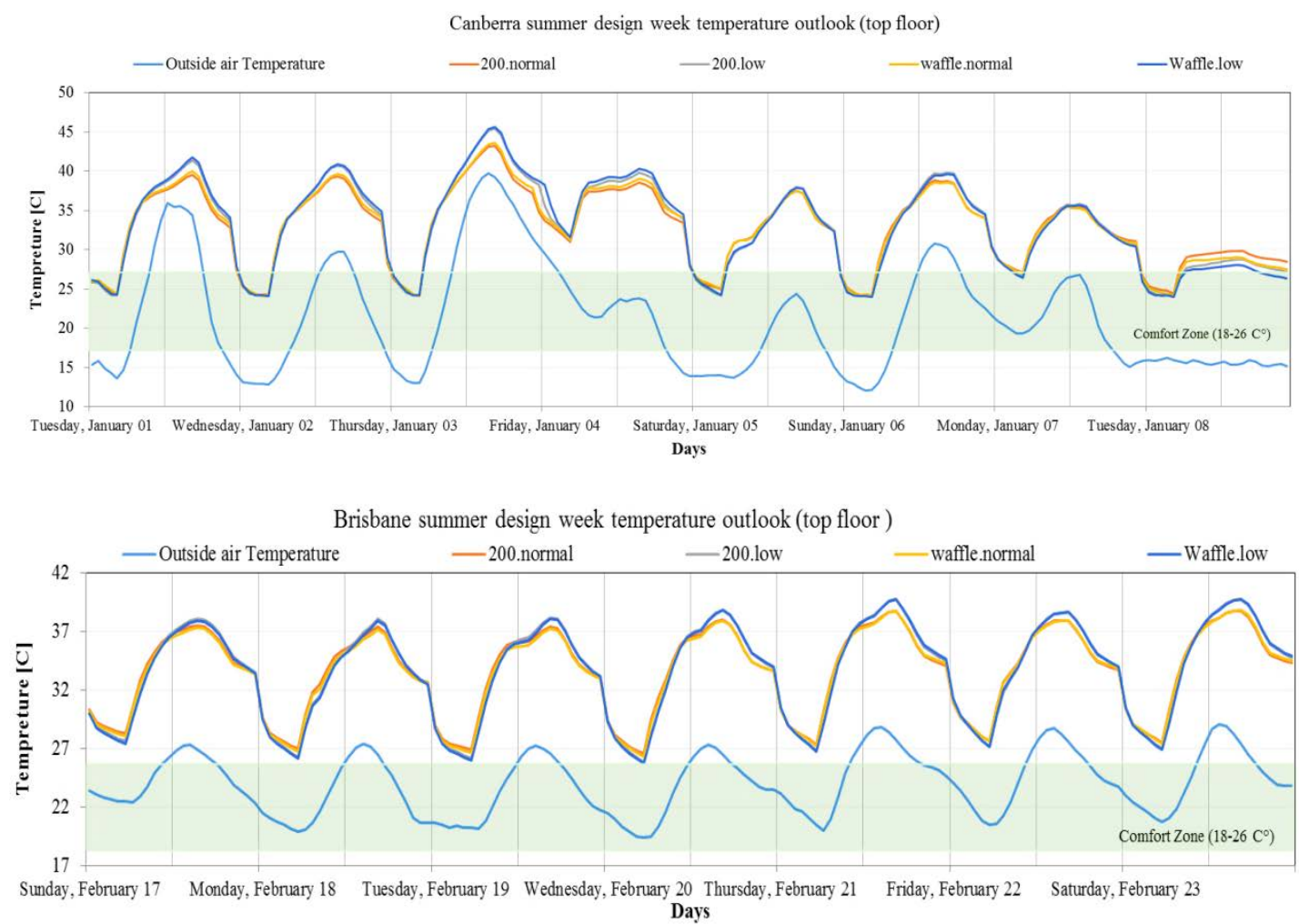

Figure 16 Analysis of Summer design week free-floating for climate zones 2 (Brisbane) and 7 (Canberra)

Table 10 shows the indoor thermal comfort conditions during operative hours ( 7 am to $9 \mathrm{pm}$ ) in the summer and winter design week. The accumulated degrees Celsius by which the hourly indoor air temperature was higher or lower than the desired comfort 
temperature (26 and $18^{\circ} \mathrm{C}$, respectively in this case) were defined here as discomfort degree hours (DDH) [37]. The results show that the DDH were almost 5\% higher in the building constructed from Ultra-lightweight concrete across all climates during the summer design week. The heavy buildings with Normal weight concrete reached a lower DDH (up to 50\%) than the Ultra-lightweight concrete in cold climates (zones 6 and 7) during the winter design week. Note that those buildings with same type of concrete had a similar performance during the summer and winter design weeks.

Table 10 Summary of discomfort degree hours during the design weeks

\begin{tabular}{|c|c|c|c|c|c|c|c|c|c|}
\hline \multirow{2}{*}{\multicolumn{2}{|c|}{$\begin{array}{l}\text { Major cities } \\
\text { (climate) }\end{array}$}} & \multicolumn{4}{|c|}{ Summer design week } & \multicolumn{4}{|c|}{ Winter design week } \\
\hline & & $\begin{array}{c}\text { 200.norm } \\
\text { al }\end{array}$ & 200.low & $\begin{array}{c}\text { Waffle.nor } \\
\text { mal }\end{array}$ & $\begin{array}{c}\text { Waffle.lo } \\
\mathrm{w}\end{array}$ & $\begin{array}{c}\text { 200.norm } \\
\text { al }\end{array}$ & $\begin{array}{c}200 . l o \\
\text { w }\end{array}$ & $\begin{array}{c}\text { Waffle.nor } \\
\text { mal }\end{array}$ & $\begin{array}{c}\text { Waffle.lo } \\
\mathrm{w}\end{array}$ \\
\hline \multirow{3}{*}{$\begin{array}{c}\text { Canberra } \\
\text { (7) }\end{array}$} & $\begin{array}{c}\text { N.DD } \\
H\end{array}$ & 112 & 112 & 112 & 112 & 57 & 57 & 57 & 57 \\
\hline & DDH & 1,033 & 1,064 & 1,032 & 1,064 & 136 & 167 & 146 & 171 \\
\hline & $\begin{array}{c}\text { M.DD } \\
\text { H }\end{array}$ & 5.44 & 5.60 & 5.43 & 5.60 & 0.71 & 0.87 & 0.76 & 0.89 \\
\hline \multirow{3}{*}{$\begin{array}{l}\text { Melbourn } \\
\text { e (6) }\end{array}$} & $\begin{array}{c}\text { N.DD } \\
\mathrm{H}\end{array}$ & 98 & 97 & 97 & 96 & 10 & 13 & 10 & 11 \\
\hline & $\mathrm{DDH}$ & 645 & 660 & 629 & 648 & 6 & 12 & 7 & 12 \\
\hline & $\begin{array}{c}\text { M.DD } \\
\text { H }\end{array}$ & 3.84 & 3.93 & 3.74 & 3.86 & 0.04 & 0.07 & 0.04 & 0.07 \\
\hline \multirow{3}{*}{$\begin{array}{l}\text { Sydney } \\
\text { (5) }\end{array}$} & $\begin{array}{c}\text { N.DD } \\
\mathrm{H}\end{array}$ & 98 & 98 & 98 & 98 & 53 & 54 & 51 & 52 \\
\hline & $\mathrm{DDH}$ & 1,257 & 1,295 & 1,256 & 1,299 & 106 & 137 & 109 & 138 \\
\hline & $\begin{array}{c}\text { M.DD } \\
\text { H }\end{array}$ & 7.48 & 7.71 & 7.48 & 7.73 & 0.63 & 0.81 & 0.65 & 0.82 \\
\hline \multirow{3}{*}{$\begin{array}{l}\text { Brisbane } \\
\text { (2) }\end{array}$} & $\begin{array}{c}\text { N.DD } \\
\mathrm{H}\end{array}$ & 98 & 98 & 98 & 98 & 63 & 62 & 60 & 60 \\
\hline & $\mathrm{DDH}$ & 982 & 1,008 & 969 & 1,002 & 196 & 226 & 189 & 221 \\
\hline & $\begin{array}{c}\text { M.DD } \\
\text { H }\end{array}$ & 5.85 & 6.00 & 5.77 & 5.96 & 1.17 & 1.35 & 1.13 & 1.31 \\
\hline \multirow{3}{*}{$\begin{array}{l}\text { Darwin } \\
\text { (1) }\end{array}$} & $\begin{array}{c}\text { N.DD } \\
\mathrm{H}\end{array}$ & 98 & 98 & 98 & 98 & 98 & 98 & 98 & 98 \\
\hline & $\mathrm{DDH}$ & 1,618 & 1,584 & 1,587 & 1,574 & 1,166 & 1,185 & 1,151 & 1,177 \\
\hline & $\begin{array}{c}\text { M.DD } \\
\text { H }\end{array}$ & 9.63 & 9.43 & 9.44 & 9.37 & 6.94 & 7.06 & 6.85 & 7.01 \\
\hline \multicolumn{10}{|c|}{$\begin{array}{l}\text { N.DDH: Number of discomfort hours during the design weeks (summer and winter); DDH: discomfort degree } \\
\text { hours; M.DDH: Mean discomfort degree hours. }\end{array}$} \\
\hline
\end{tabular}

The discomfort degree hours indicated that the 200.normal and Waffle.normal construction types would have a lower overheating peak (i.e lower DDH in Table 4) in summer and winter conditions than the 200.low and Waffle.low types across the five major cities studied. A good example of the different discomfort degrees hours 
(DDH) between the four construction types is given in Figure 17 for climates 1 and 6. Note that the effects of structural materials (types of concrete) and slab types (Flat and Waffle slabs) on indoor thermal conditions are slightly more noticeable in cold and moderate climates than hot and warm climates. The results of the other four climate zones are provided in Appendix D.

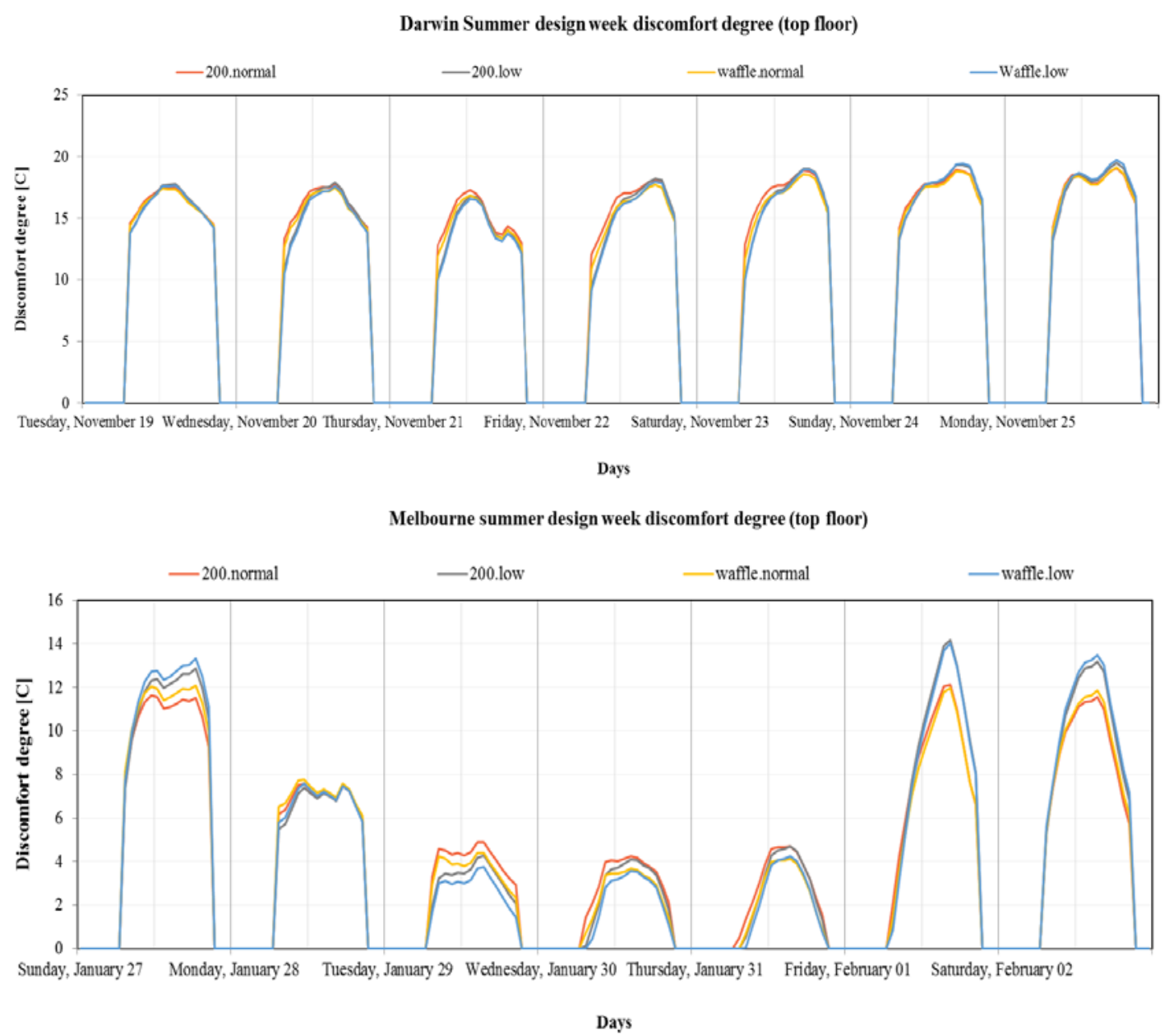

Figure 17 discomfort degree hours during summer design week for climate zones 1 (Darwin) and 6 (Melbourne)

Figures 8 to 17 show that the thermal properties of structural concrete have more influence on the thermal performance of a building than the weight of the structure; in fact the thermal properties of concrete (i.e. Ultra-lightweight versus Normal weight concrete) have a greater effect on the indoor air temperatures as the outside air temperature increases, and the differences between indoor air temperatures due to 
different structures (i.e. Flat slab versus Waffle slab) are more visible in moderate and cold climates.

\section{Conclusion}

This study aimed to evaluate the impact that alternative concrete floor designs have on the energy performance of a typical office building. This research used a benchmarking method to measure the thermal energy performance of a building using two forms of construction (Flat slab and Waffle slab) and two types of concrete (conventional Normal weight and novel Ultra-lightweight). The structural design analysis provided the maximum and minimum building mass for the Flat slab and Waffle slab respectively, which were then used to simulate the energy performance for whole buildings.

This analysis revealed how well structures with a higher thermal mass could moderate fluctuations between inside and outside air temperatures; those buildings with a higher concrete mass (thermal mass) stored more heat which then reduced the peak indoor air temperatures. Moreover, when Flat and Waffle slab structures were constructed from Normal weight concrete they had a similar energy performance, whereas Ultra-lightweight concrete resulted in indoor temperatures that were more sensitive to fluctuations in external air temperatures, so the building required more energy to achieve the desired indoor temperature range.

This comparative analysis also revealed that choosing the appropriate type of concrete and construction form could reduce the annual cooling energy demand by a highly-glazed office building by $14 \%$ in the colder climate zones and by $3 \%$ in warmer and hot climates.

The hourly free-floating simulation showed that a building with Ultra-lightweight concrete would experience higher daily peak indoor air temperatures during daytime, 
while the Lightweight building with Novel Ultra-lightweight experienced large increases of peak indoor air temperatures during the design weeks (Summer and Winter) by $1.2^{\circ} \mathrm{C}$ to $2.4^{\circ} \mathrm{C}$ in the hot and cold climate zones, respectively; in fact this type of highly glazed office building risked overheating during the summer and winter periods.

These indoor thermal conditions confirm that buildings where conventional Normal weight concrete is used for the structural elements (slabs, columns and shear walls) had less discomfort degree hours during the design weeks than the novel Ultralightweight concrete.

Finally, an appropriate structural design in which the energy performance is also considered could lead to reductions in the thermal energy demand for office buildings. This study highlights how important it is to look beyond the designed structural system and evaluate its impact with a holistic analysis. A similar approach as in this study could be used to assess the potential effect of other structural designs on various types of buildings by considering alternative framing systems and materials such as a cross laminated timber system and a Post-tensioned floor system. 
APPENDIX A: DETAILED STRUCTURAL DESIGN

Table A-1 Flat slab detailed structural design

\begin{tabular}{|c|c|c|c|c|c|c|c|c|c|c|c|}
\hline \multicolumn{12}{|c|}{ Structure details- Flat slab } \\
\hline \multicolumn{3}{|c|}{ Structure elements } & $\begin{array}{l}\text { Size of } \\
\text { element } \\
\text { (Cross } \\
\text { section) } \\
\text { (mm) }\end{array}$ & 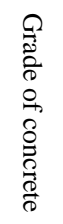 & 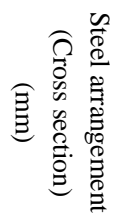 & 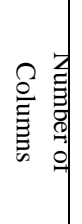 & 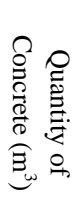 & 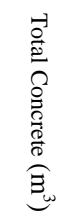 & 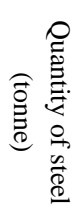 & $\begin{array}{l}\text { o̊ } \\
\underset{\mathbb{P}}{D} \\
\stackrel{D}{D}\end{array}$ & 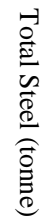 \\
\hline \multirow{10}{*}{$\frac{\cap}{\stackrel{\rho}{\xi}}$} & \multirow{2}{*}{$\begin{array}{c}\text { Level } 1 \\
\text { to } 3\end{array}$} & Interior & $500 \times 500$ & \multirow{10}{*}{ N40 } & $10 \mathrm{~N} 32$ & 24 & 20 & \multirow{10}{*}{93} & 18 & $3 \%$ & \multirow{10}{*}{83} \\
\hline & & perimeter & $350 \times 350$ & & $8 \mathrm{~N} 28$ & 24 & 10 & & 11 & $4 \%$ & \\
\hline & \multirow{2}{*}{$\begin{array}{l}\text { Level } 4 \\
\text { to } 6\end{array}$} & Interior & $400 \times 400$ & & $10 \mathrm{~N} 28$ & 24 & 13 & & 13 & $4 \%$ & \\
\hline & & perimeter & $325 \times 325$ & & $8 \mathrm{~N} 24$ & 24 & 8 & & 8 & $3 \%$ & \\
\hline & \multirow{2}{*}{$\begin{array}{c}\text { Level } 7 \\
\text { to } 9\end{array}$} & Interior & $375 \times 375$ & & $10 \mathrm{~N} 20$ & 24 & 11 & & 7 & $2 \%$ & \\
\hline & & perimeter & $300 \times 300$ & & 8 N 20 & 24 & 7 & & 6 & $3 \%$ & \\
\hline & \multirow{2}{*}{$\begin{array}{c}\text { Level } \\
10 \text { to } \\
12\end{array}$} & Interior & $375 \times 375$ & & $8 \mathrm{~N} 24$ & 24 & 8 & & 8 & $3 \%$ & \\
\hline & & perimeter & $300 \times 300$ & & 8 N 20 & 24 & 5 & & 6 & $3 \%$ & \\
\hline & \multirow{2}{*}{$\begin{array}{c}\text { Level } \\
13 \text { to } \\
15\end{array}$} & Interior & $275 \times 275$ & & 6 N 16 & 24 & 6 & & 2 & $3 \%$ & \\
\hline & & perimeter & $250 \times 250$ & & $8 \mathrm{~N} 16$ & 24 & 5 & & 4 & $3 \%$ & \\
\hline$\frac{\tilde{g}}{\tilde{\sigma}}$ & \multicolumn{2}{|c|}{$\begin{array}{l}\text { Suspended floor with } \\
\text { drop panel }\end{array}$} & $\begin{array}{l}200 \mathrm{~mm} \\
\text { (depth) }\end{array}$ & N32 & \multicolumn{2}{|c|}{$\begin{array}{c}\text { Column strip \& } \\
\text { Mid span: Top- } \\
\text { N12@150 mm; } \\
\text { Bot- N12@100 } \\
\text { mm (Same for } \\
\text { both directions)+ } \\
\text { Drop panel } \\
\text { (N12@ } 300 \text { mm) }\end{array}$} & 2469 & 3,000 & 654 & $\begin{array}{c}0.56 \\
\%\end{array}$ & 654 \\
\hline \multicolumn{3}{|c|}{ Wall } & $\begin{array}{c}200 \text { mm } \\
\text { (thickness) }\end{array}$ & N40 & \multicolumn{2}{|c|}{$\begin{array}{l}\text { N12@300 mm } \\
\text { both sides (Top } \\
\text { \& Bottom) }\end{array}$} & --- & 31 & 9 & $4 \%$ & 9 \\
\hline \multicolumn{3}{|c|}{ Staircase } & $\begin{array}{c}15 \mathrm{~mm} \\
\text { (thickness) }\end{array}$ & N20 & \multicolumn{2}{|c|}{$\begin{array}{l}\text { N12@200 mm } \\
\text { both directions }\end{array}$} & --- & 250 & 7 & $1 \%$ & 7 \\
\hline
\end{tabular}


Table A-2 Waffle slab detailed structural design

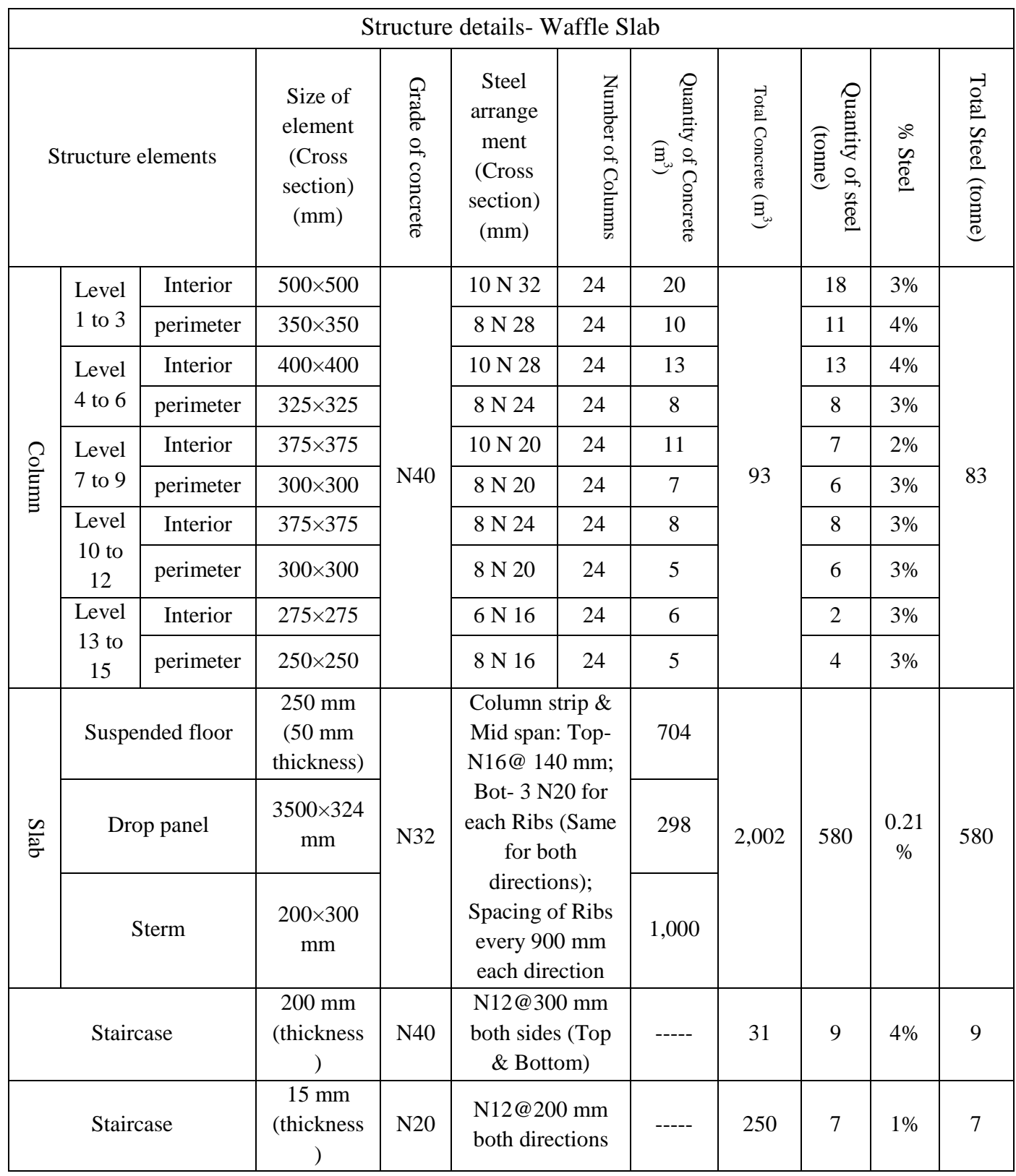




\section{APPENDIX B: HOURLY AIR ROOM TEMPERATURE PLOTTED}

\section{AGAINST THE HOURLY OUTDOOR TEMPERATURE}

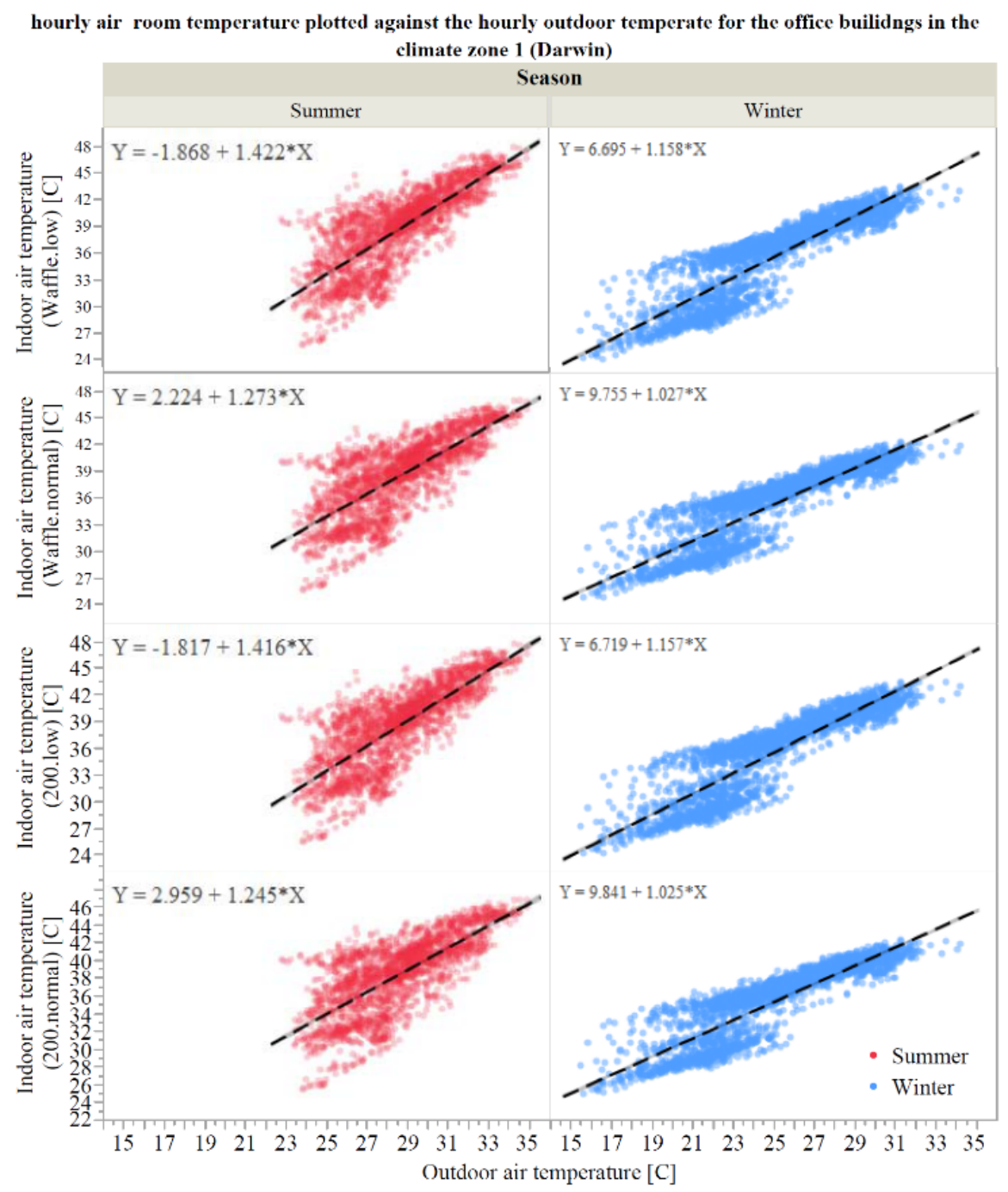

Figure B-1 hourly air room temperature plotted against the hourly outdoor temperate for the Waffle.low and 200.normal in the climate zone 1 (Darwin). 
hourly air room temperature plotted against the hourly outdoor temperate for the office builidngs in the climate zone 5 (Sydney)

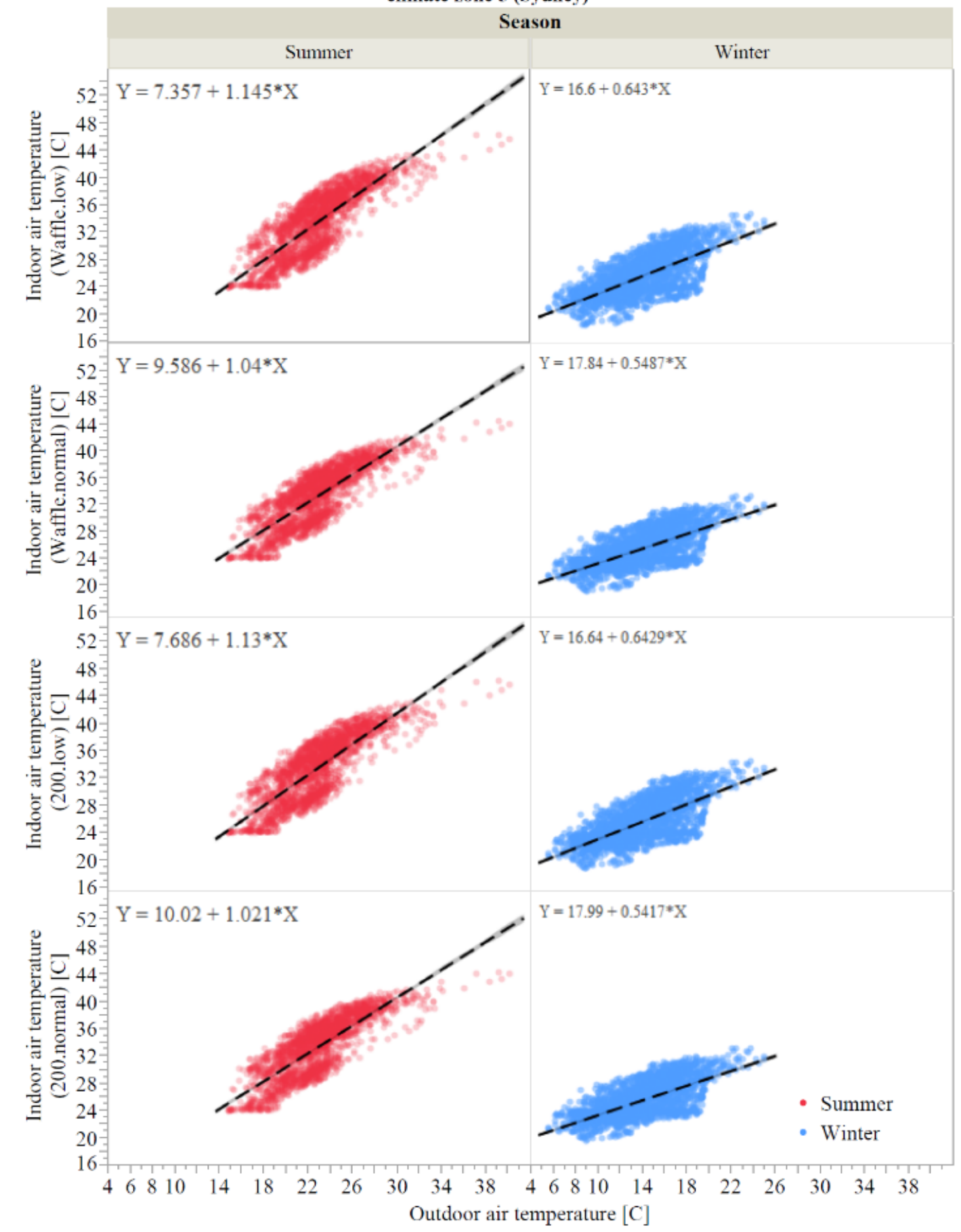

Figure B-2 hourly air room temperature plotted against the hourly outdoor temperate for the Waffle.low and 200.normal in the climate zone 5 (Sydney). 
hourly air room temperature plotted against the hourly outdoor temperate for the office builidngs in the climate zone 6 (Melbourne)

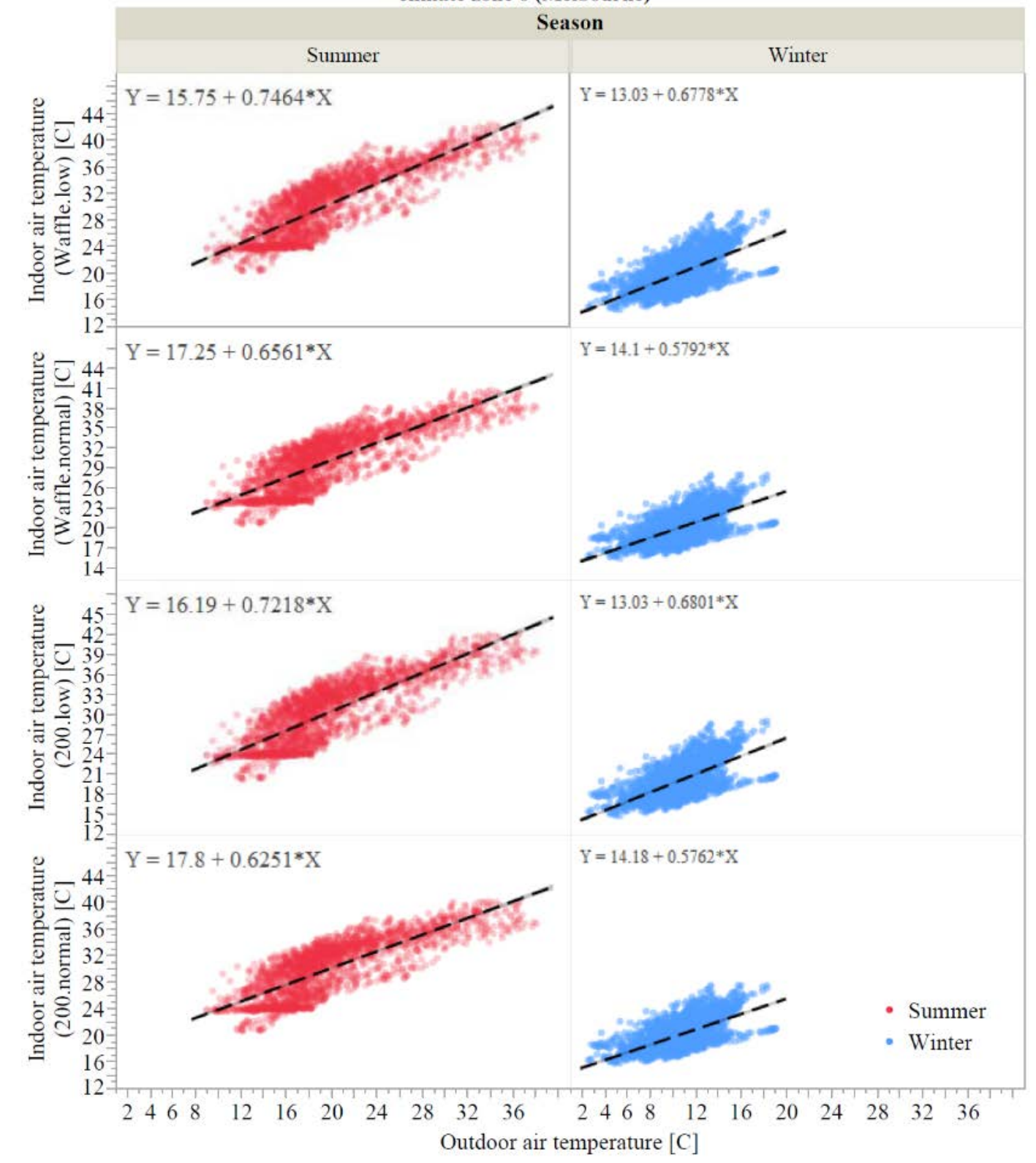

Figure B-3 hourly air room temperature plotted against the hourly outdoor temperate for the Waffle.low and 200.normal in the climate zone 6 (Melbourne). 
hourly air room temperature plotted against the hourly outdoor temperate for the office builidngs in the climate zone 7 (Canberra)

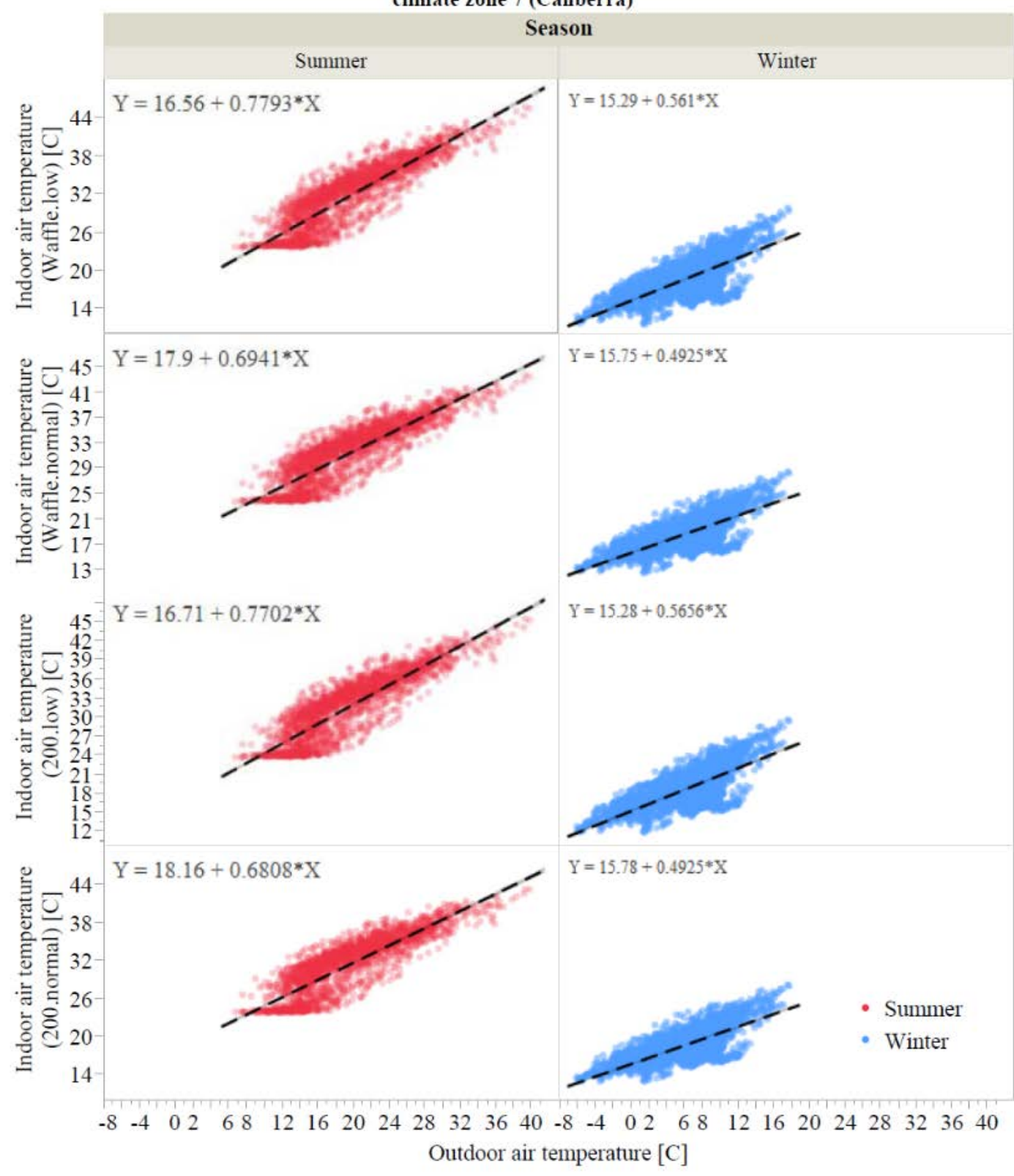

Figure B-4 hourly air room temperature plotted against the hourly outdoor

temperate for the Waffle.low and 200.normal in the climate zone 7 (Canberra). 
APPENDIX C: SUMMER AND WINTER DESIGN WEEK - FREE FLOATING INDOOR AIR TEMPERATURE

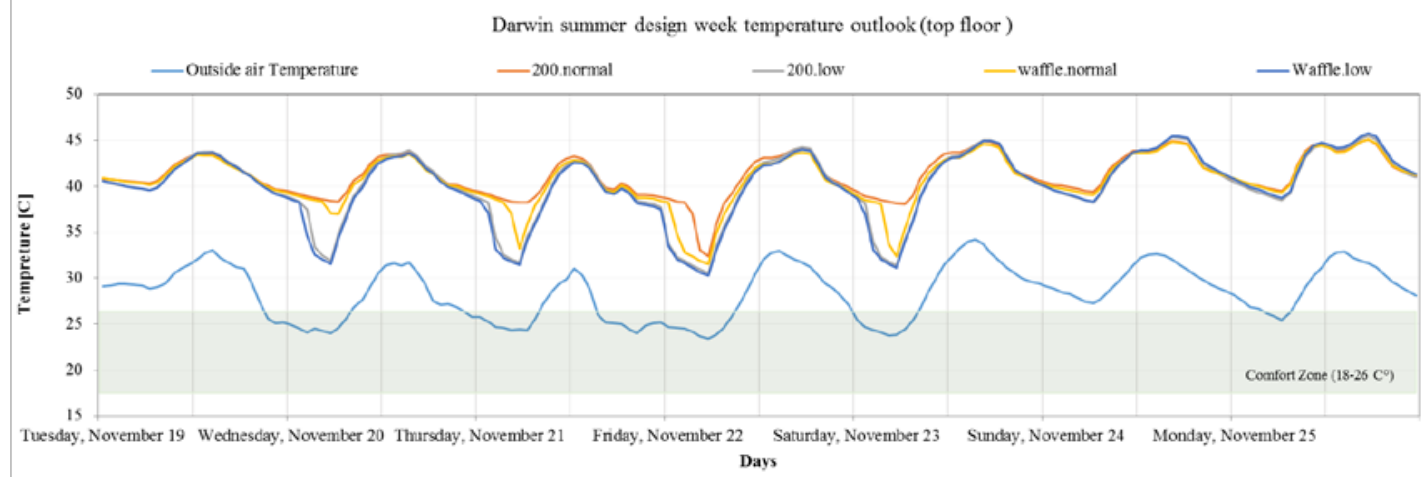

Figure C-1 Summer design week free-floating analysis for climate zones 1 (Darwin)

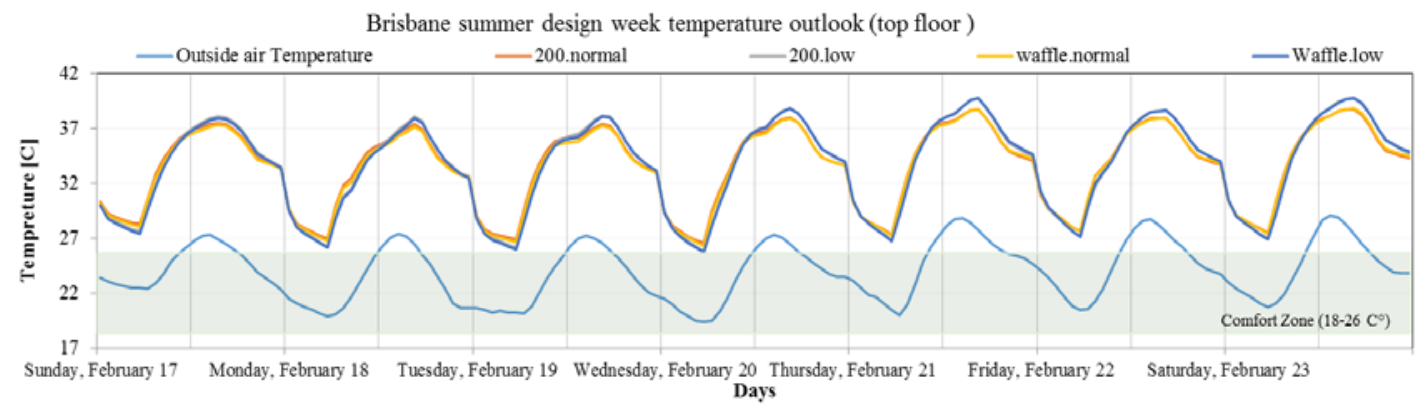

Figure C-2 Summer design week free-floating analysis for climate zones 2 (Brisbane)

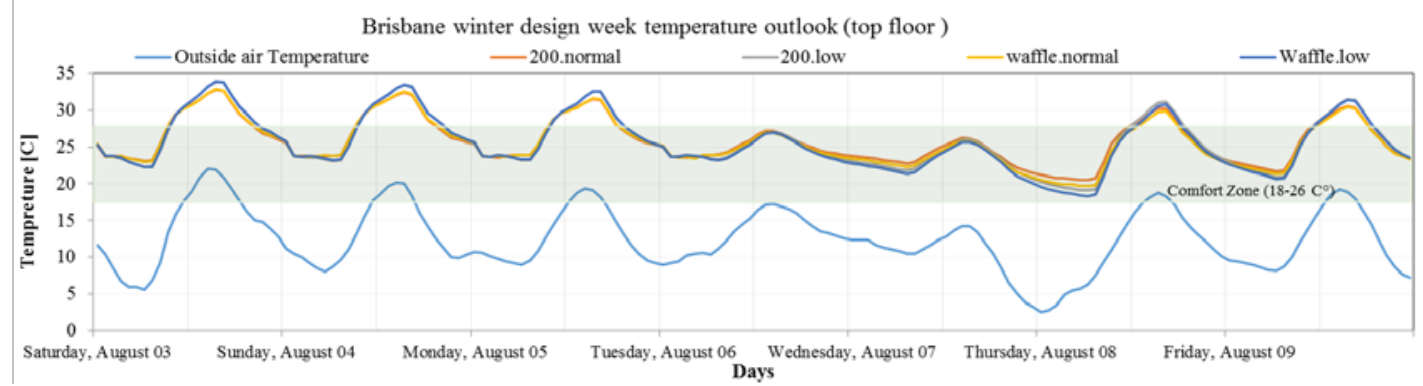

Figure C-3 Winter design week free-floating analysis for climate zones 2

(Brisbane)

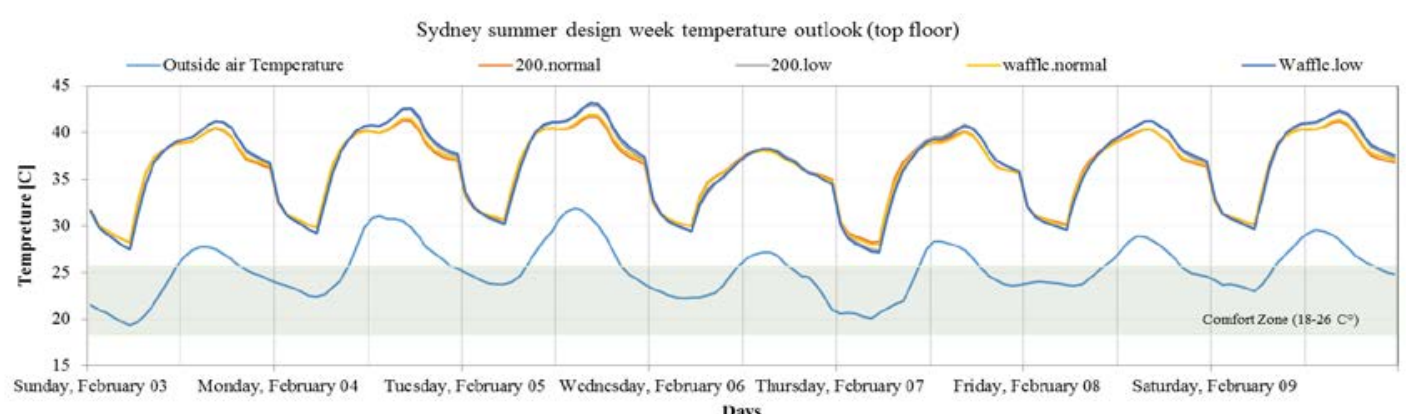

Figure C-4 Summer design week free-floating analysis for climate zones 5 (Sydney) 


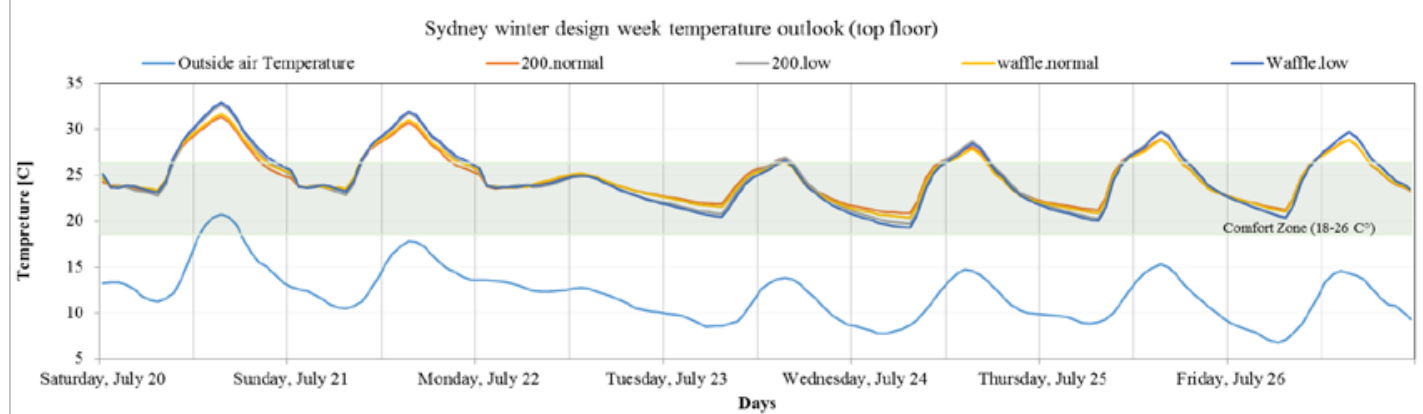

Figure C-5 Winter design week free-floating analysis for climate zones 5 (Sydney)

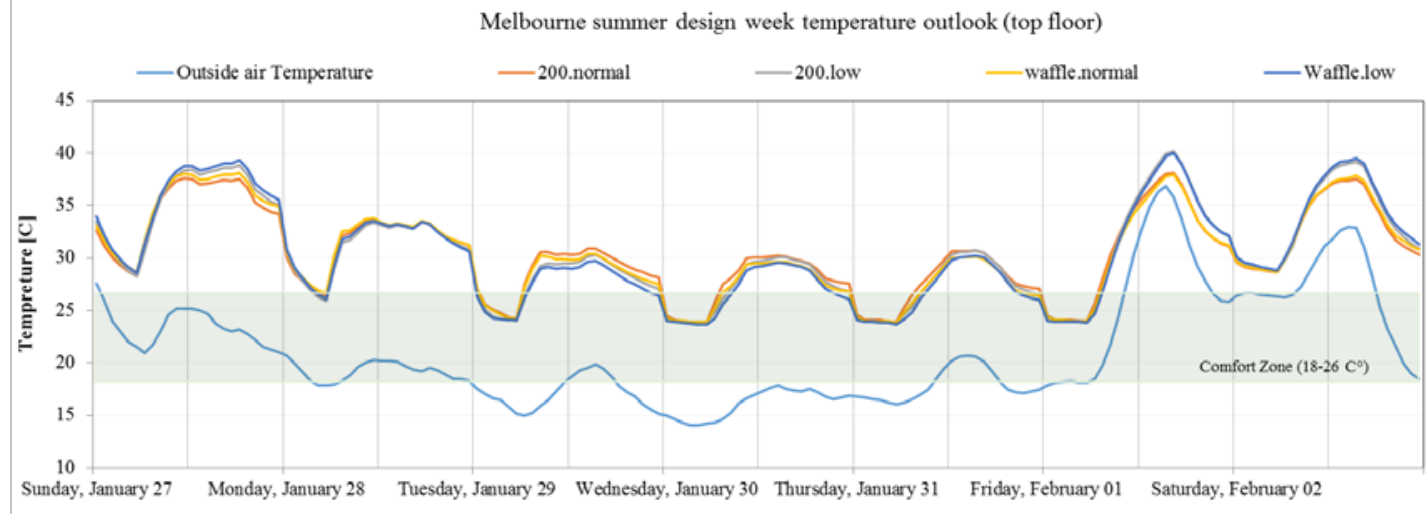

Days

Figure C-6 Summer design week free-floating analysis for climate zones 6 (Melbourne)

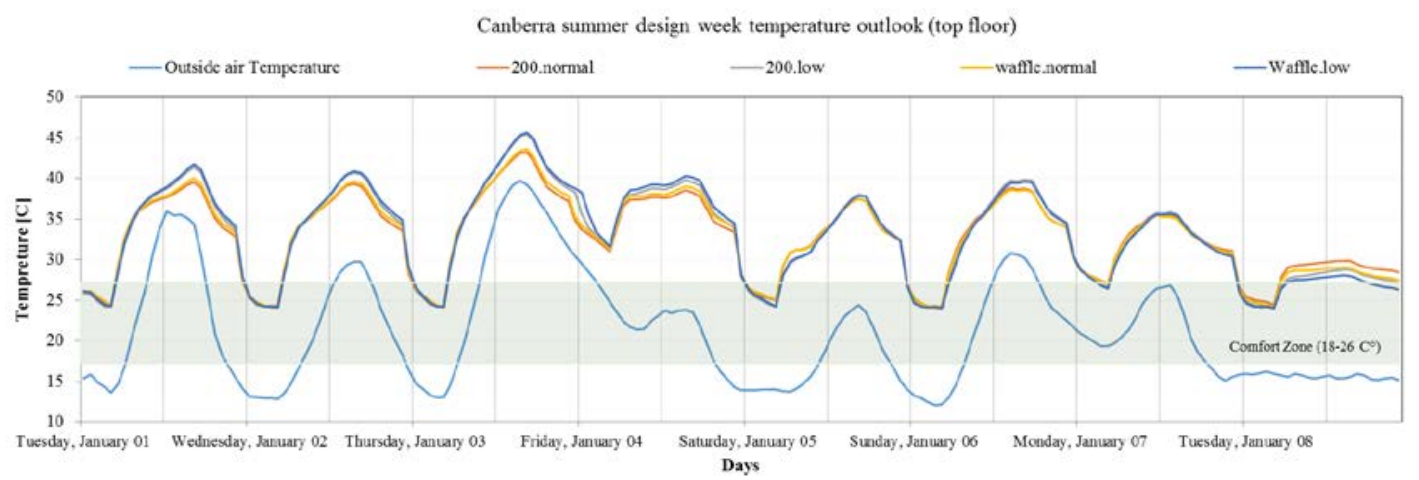

Figure C-7 Summer design week free-floating analysis for climate zones 7

(Canberra)

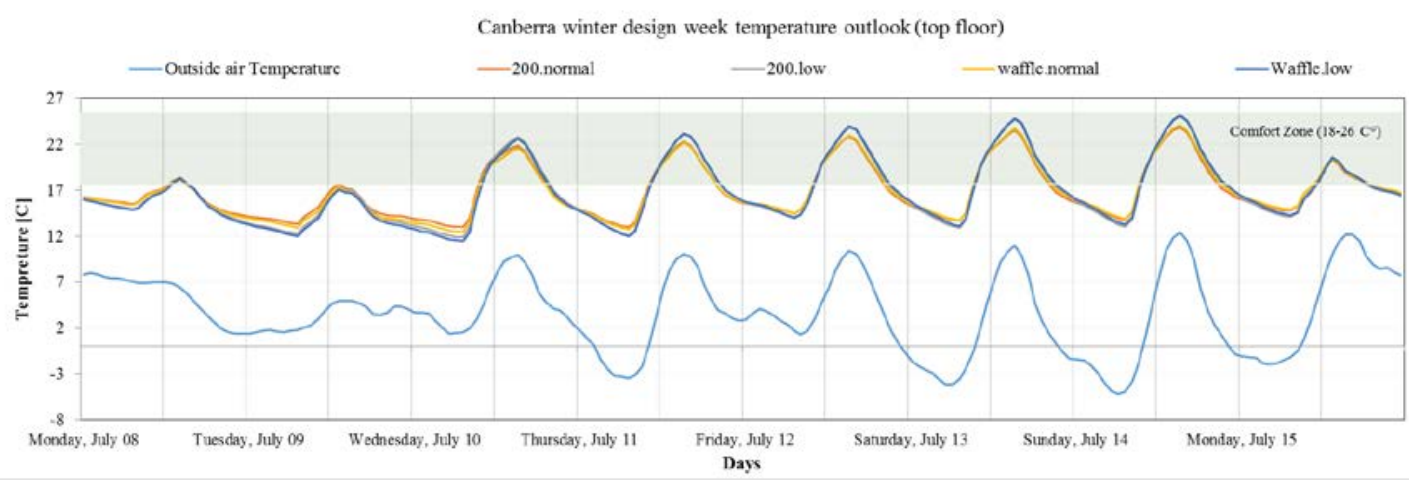

Figure C-8 Winter design week free-floating analysis for climate zones 7

(Canberra) 
APPENDIX D: DISCOMFORT DEGREE HOURS DURING THE DESIGN WEEKS

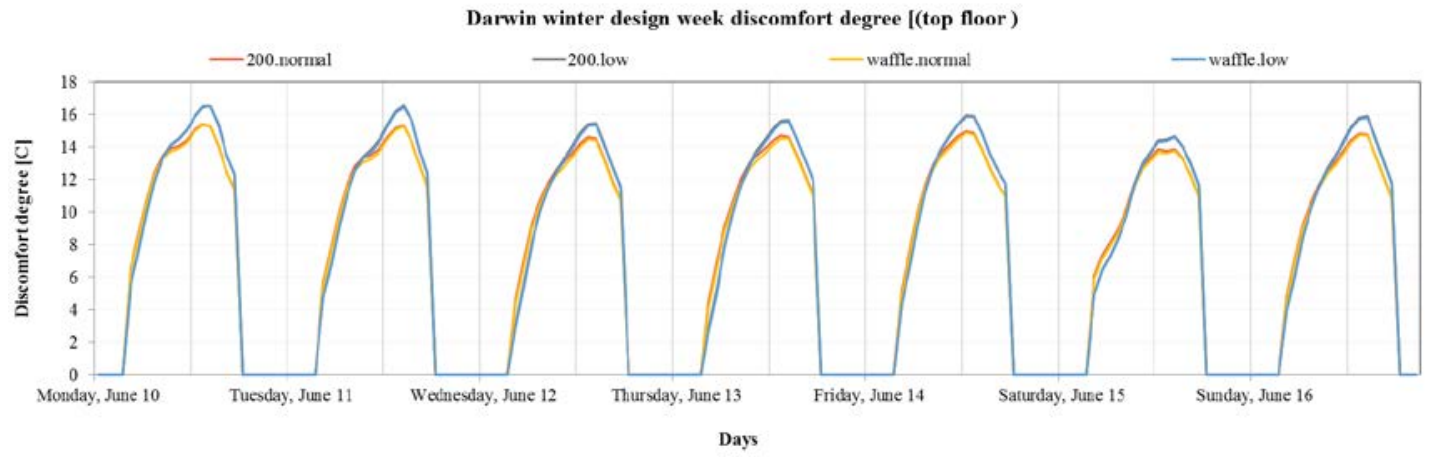

Figure D-1 discomfort degree hours during winter design week for climate zones 1 (Darwin)

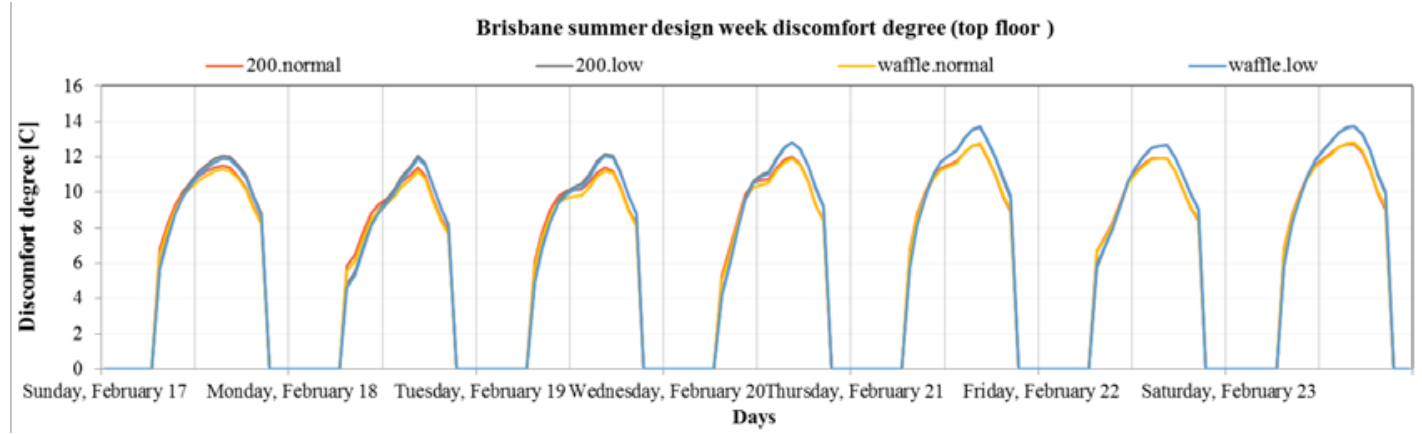

Figure D-2 discomfort degree hours during summer design week for climate zones 2 (Brisbane)

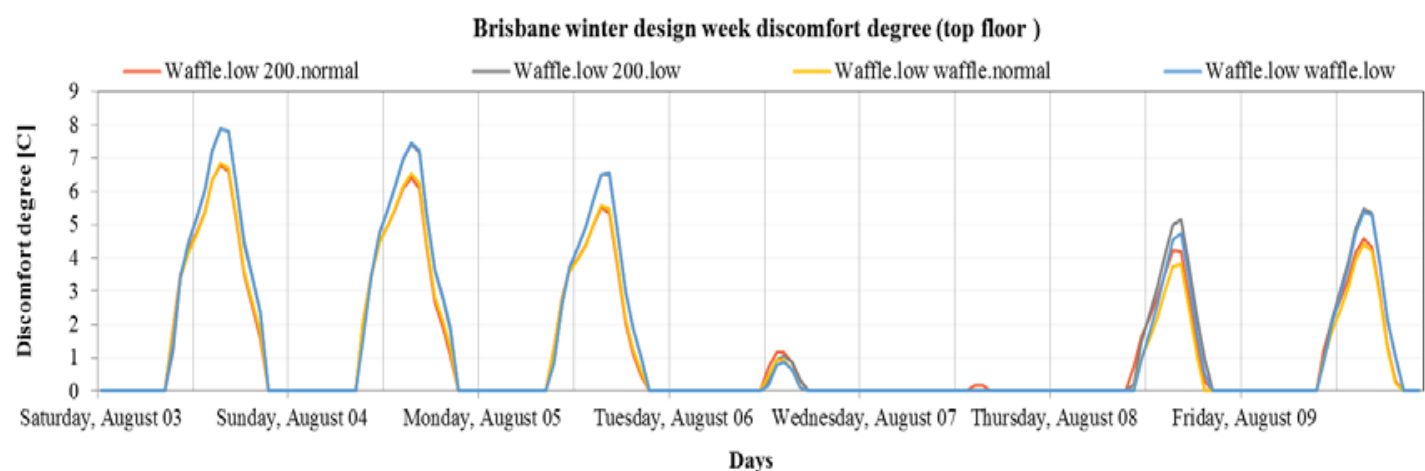

Figure D-3 discomfort degree hours during winter design week for climate zones 2 (Brisbane)

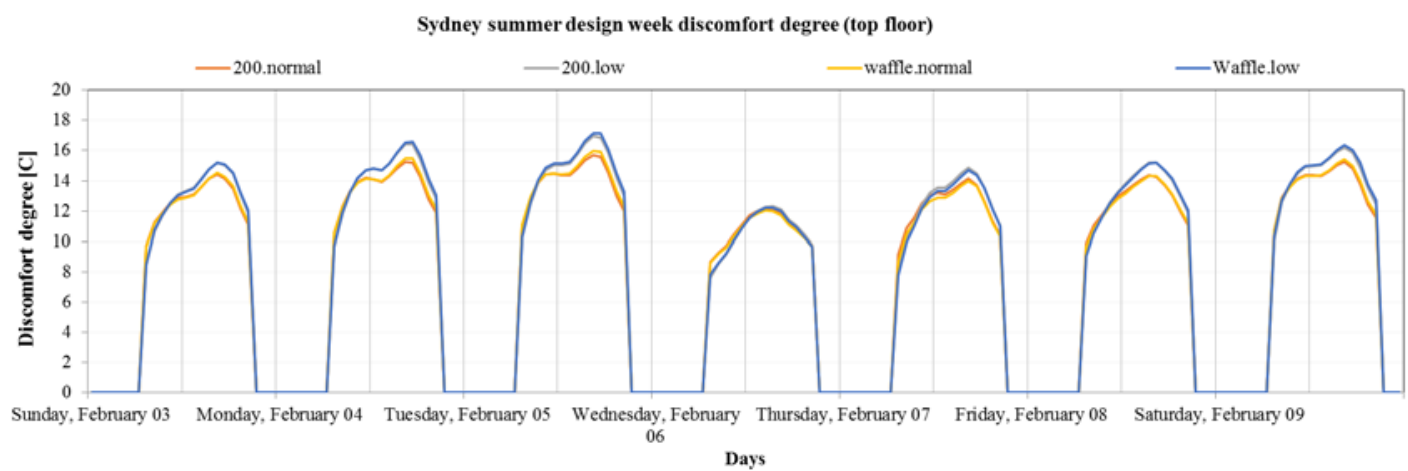

Figure D-4 discomfort degree hours during summer design week for climate zones 5 (Sydney) 


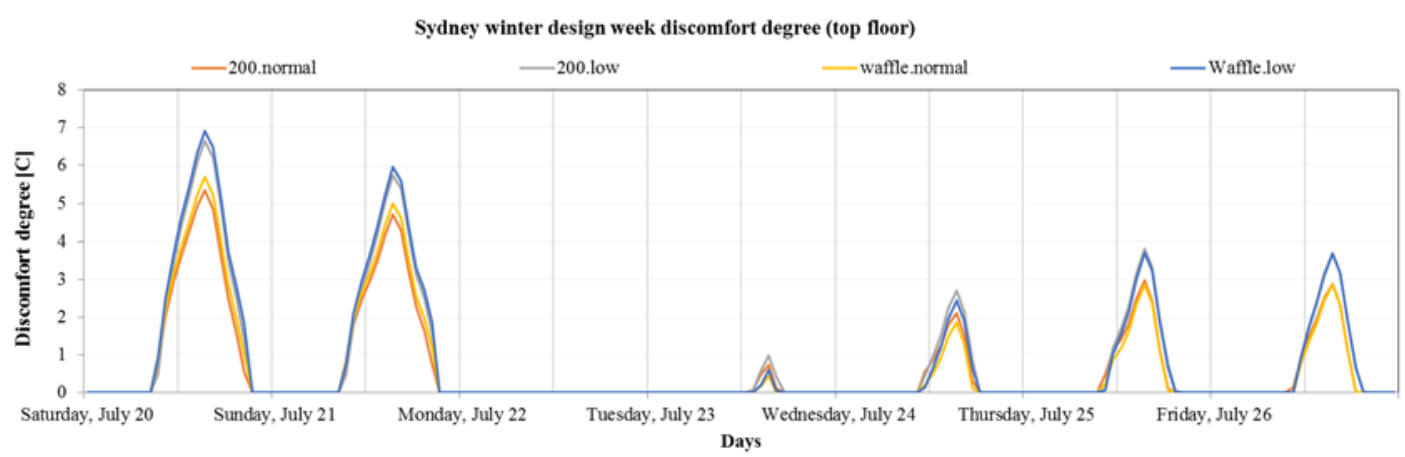

Figure D-5 discomfort degree hours during winter design week for climate zones 5 (Sydney)

Melbourne design week discomfort degree (top floor)

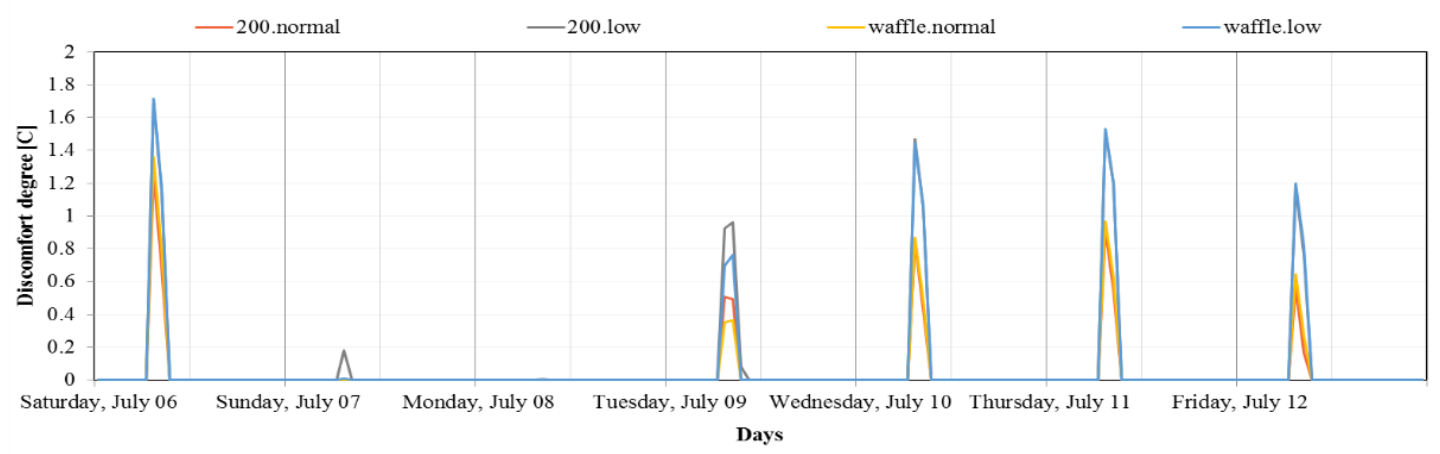

Figure D-6 discomfort degree hours during winter design week for climate zones 6 (Melbourne)

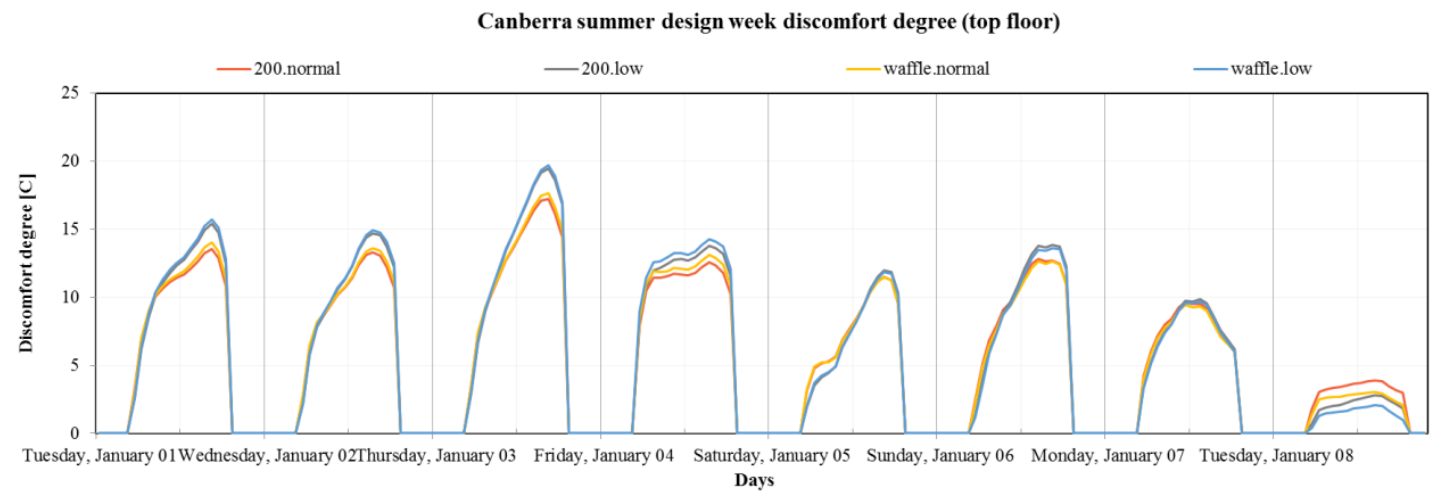

Figure D-7 discomfort degree hours during summer design week for climate zones 7 (Canberra) 


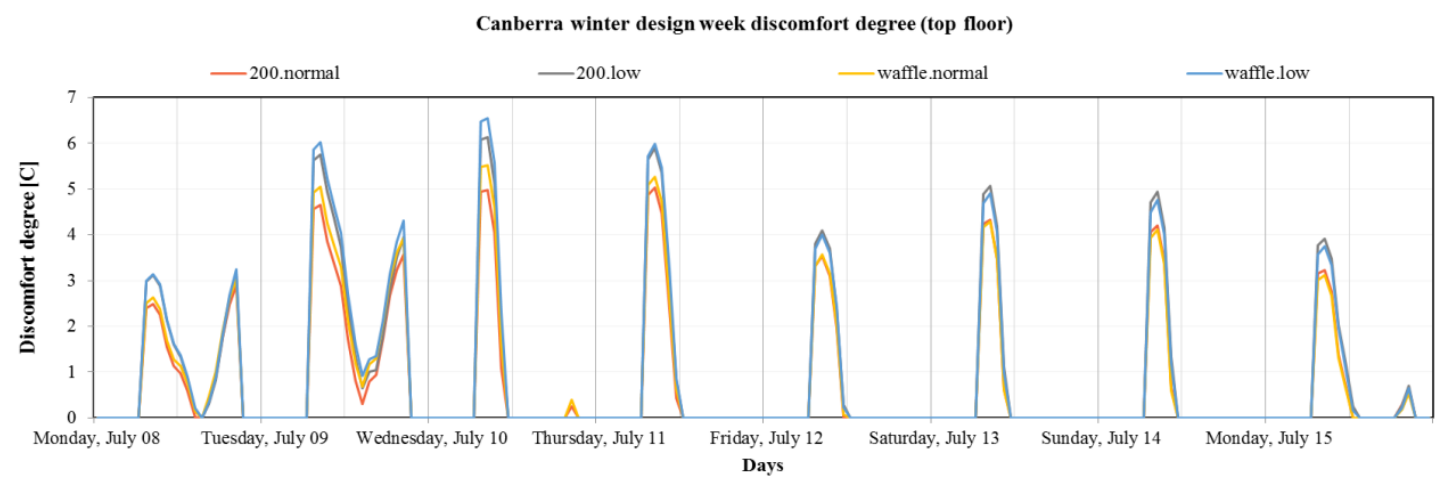

Figure D-8 discomfort degree hours during winter design week for climate zones 7 (Canberra) 


\section{References}

[1] F.P. Torgal, S. Jalali, Eco-efficient construction and building materials, London Limited: Springer Verlag, (2011).

[2] B. Zhang, C.S. Poon, Use of Furnace Bottom Ash for producing lightweight aggregate concrete with thermal insulation properties, Journal of Cleaner Production, 99 (2015) 94-100.

[3] Y. Wu, J.-Y. Wang, P.J.M. Monteiro, M.-H. Zhang, Development of ultralightweight cement composites with low thermal conductivity and high specific strength for energy efficient buildings, Construction and Building Materials, 87 (2015) 100-112.

[4] T.S. Yun, Y.J. Jeong, T.-S. Han, K.-S. Youm, Evaluation of thermal conductivity for thermally insulated concretes, Energy and Buildings, 61 (2013) 125-132.

[5] S. Marinkovic, V. Radonjanin, M. Malesev, I. Ignjatovic, Comparative environmental assessment of natural and recycled aggregate concrete, Waste Manag, 30 (11) (2010) 2255-2264.

[6] M. Robati, T.J. McCarthy, G. Kokogiannakis, Incorporating environmental evaluation and thermal properties of concrete mix designs, Construction and Building Materials, 128 (2016) 422-435.

[7] A.M. Neville, Properties of concrete, Prentice Hall, London, UK, 2012.

[8] M.M.A.B. Abdullah, K. Hussin, M. Bnhussain, K.N. Ismail, Z. Yahya, R. Abdul Razak, Fly ash-based geopolymer lightweight concrete using foaming agent, International journal of molecular sciences, 13 (6) (2012) 7186-7198.

[9] P. Nuaklong, V. Sata, P. Chindaprasirt, Influence of recycled aggregate on fly ash geopolymer concrete properties, Journal of Cleaner Production, 112 (2016) 23002307.

[10] ACI122R, Guide to Thermal Properties of Concrete and Masonry Systems, American Concrete Institute, 2014.

[11] CCAA, Green Star Mat-4 Concrete Credit User Guide, Cement Concrete \& Aggregates Australia, (2015).

[12] M.L. Berndt, Influence of concrete mix design on CO2 emissions for large wind turbine foundations, Renewable Energy, 83 (2015) 608-614.

[13] O. Damdelen, C. Georgopoulos, M. Limbachiya, Measuring thermal Mass of sustainable concrete mixes, Scholars' Press, 2015.

[14] N. Tošić, S. Marinković, T. Dašić, M. Stanić, Multicriteria optimization of natural and recycled aggregate concrete for structural use, Journal of Cleaner Production, 87 (2015) 766-776.

[15] L.M. O'Moore, K.R. O'Brien, Impact of supplementary cementitious material content and transportation distance on greenhouse gas emissions embodied in concrete, in: 24th Biennial Conference of Concrete Institute of Australia (Concrete 09), Concrete Institute of Australia, 2009, pp. 1-9.

[16] P. Hoes, M. Trcka, J.L.M. Hensen, B. Hoekstra Bonnema, Investigating the potential of a novel low-energy house concept with hybrid adaptable thermal storage, Energy Conversion and Management, 52 (6) (2011) 2442-2447.

[17] F. Roberz, R.C.G.M. Loonen, P. Hoes, J.L.M. Hensen, Ultra-lightweight concrete: Energy and comfort performance evaluation in relation to buildings with low and high thermal mass, Energy and Buildings, 138 (2017) 432-442. 
[18] M. Gjerde, Retrofitting thermal mass into New Zealand houses: what are the potential benefits, in: 49th Associated School of Construction Annual International Conference, 2013.

[19] F. Calcerano, C. Cecchini, Mediterranean Buildings Refurbishment: Thermal Mass and Natural Ventilation Simulated Control, in: Fifth German-Austrian IBPSA Conference RWTH, Aachen University, Bausim, Germany, 2014, pp. 136-143.

[20] D.M.A. Huiskes, A. Keulen, Q.L. Yu, H.J.H. Brouwers, Design and performance evaluation of ultra-lightweight geopolymer concrete, Materials \& Design, 89 (2016) 516-526.

[21] Q.L. Yu, P. Spiesz, H.J.H. Brouwers, Ultra-lightweight concrete: Conceptual design and performance evaluation, Cement and Concrete Composites, 61 (2015) 18-28.

[22] NS11401.1, Labelling and declaration of environmental attributes of building products- Type III environmental declarations, in: Part 1: Whole of structure, whole of life, benchmark method, National Standards Development Organisation Limited, Australia, 2014.

[23] B.Z. Emissions, Zero Carbon Australia Buildings Plan, Melbourne: Melbourne Energy Institute, University of Melbourne, (2013).

[24] AS3600, Concrete Structures, in, Standards Australia International Ltd, Sydney, 2009.

[25] AS/NZ1170.0, Part0: General principles Structure design actions, in, Australian/ New Zealand Standard, 2002.

[26] AS/NZ1170.2, Part 2: Wind Actions, in, Australian/ New Zealand Standard, 2002.

[27] EnergyPlus, Weather data sources, in, U.S. Department of Energy's (DOE) Building Technologies Office (BTO), 2017.

[28] ABCB, National construction code, Australian Building Codes Board, Canberra, 2015.

[29] DesignBuilder, HVAC Model Option, in, DesignBuilder Software Ltd, UK, 2017.

[30] A.M. Egan, Air tightness of Australian offices buildings: reality versus typical assumption used in energy performance simulation, in: 12th Conference of International Building Performance Simulation Association, International Building Performance Simulation Association, Sydney, Australia, 2011.

[31] Pitt\&Sherry, Baseline energy consumption and greenhouse gas emissions In commercial buildings in Australia, in: Part 1 - Report, Council of Australian Governments (COAG) National Strategy on Energy Efficiency, 2012.

[32] ICANZ, Insulation handbook part 1: Thermal Performance, in, Insulation Council of Australia and New Zealand, 2010, pp. 32.

[33] D. Daly, P. Cooper, Z. Ma, Understanding the risks and uncertainties introduced by common assumptions in energy simulations for Australian commercial buildings, Energy and Buildings, 75 (2014) 382-393.

[34] L. Guan, Implication of global warming on air-conditioned office buildings in Australia, Building Research \& Information, 37 (1) (2009) 43-54.

[35] BOM, Mean monthly and mean annual heating and cooling degree days data (base climatological data sets), in: B.o. Meteorology (Ed.), Australia, Victoria, Australia, 2011.

[36] P. Bannister, Australian building codes board: Class 5 benchmarking, in, Canberra, Australia, 2004. 
[37] S. Ferrari, V. Zanotto, Building energy performance assessment in Southern Europe, Springer, 2015. 